\title{
A genomic perspective on the potential of termite-associated Cellulosimicrobium cellulans MP1 as producer of plant biomass-acting enzymes and exopolysaccharides
}

\author{
Nguyen Thi-Hanh Vu ${ }^{\text {Equal first author, 1, } 2}$, Tung Ngoc Quach ${ }^{\text {Equal first author, 1,2 }}$, Xuan Thi-Thanh Dao ${ }^{3,4}$, Ha Thanh Le ${ }^{\text {Corresp., }}{ }^{3}$, Chi \\ Phuong Le ${ }^{1}$, Lam Tung Nguyen ${ }^{3}$, Lam Tung Le ${ }^{1}$, Cuong Cao Ngo ${ }^{5}$, Ha Hoang ${ }^{1}$, Ha Hoang Chu ${ }^{1,2}$, Quyet-Tien Phi \\ Corresp. 1, 2 \\ ${ }^{1}$ Institute of Biotechnology, Vietnam Academy of Science and Technology, Hanoi, Vietnam, Hanoi, Vietnam \\ 2 Graduate University of Science and Technology, Vietnam Academy of Science and Technology, Hanoi, Vietnam \\ 3 School of Biotechnology and Food Technology, Hanoi University of Science and Technology, Hanoi, Vietnam \\ 4 Vinh University, Vinh, Vietnam \\ 5 Vietnam - Russia Tropical Center, Hanoi, Vietnam \\ Corresponding Authors: Ha Thanh Le, Quyet-Tien Phi \\ Email address: ha.lethanh@hust.edu.vn, tienpq@ibt.ac.vn
}

Background. Lignocellulose is a renewable and enormous biomass resource, which can be degraded efficiently by a range of cocktails of carbohydrate-active enzymes secreted by termite gut symbiotic bacteria. The urgent need to find enzymes with novel characteristics is required for improving the conversion processes in the production of lignocellulosic-based products. Although various studies dedicated to the genus Cellulosimicrobium as gut symbiont, genetic potential related to plant biomassacting enzymes and exopolysaccharides production has been fully untapped to date.

Methods. The cellulolytic bacterial strain MP1 was isolated from termite guts and identified to the species level by phenotypic, phylogenetic, and genomic analysis. To further explore genes related to cellulose and hemicellulose degradation, the draft genome of strain MP1 was obtained by using wholegenome sequencing, assembly, and annotation through the Illumina platform. Lignocellulose degrading enzymes and levan production in the liquid medium were also examined to shed light on bacterial activities.

Results. Among 65 isolates obtained, the strain MP1 was the most efficient cellulase producer with cellulase activity of $0.65 \pm 0.02 \mathrm{IU} / \mathrm{ml}$. The whole genome analysis depicted that strain MP1 consists of a circular chromosome that contained 4,580,223 bp with an average GC content of $73.9 \%$. The genome comprises 23 contigs including 67 rRNA genes, 3 tRNA genes, a single tmRNA gene, and 4,046 proteincoding sequences. In support of the phenotypic identification, the 16S rRNA gene sequence, average nucleotide identity, and whole-genome-based taxonomic analysis demonstrated that the strain MP1 belongs to the species Cellulosimicrobium cellulans. A total of 30 genes related to the degradation of cellulases and hemicellulases were identified in the $C$. cellulans MP1 genome. Of note, the presence of sacC1-levB-sacC2-Is operon responsible for levan and levan-type fructooligosaccharides biosynthesis was detected in strain MP1 genome, but not with closely related $C$. cellulans strains, proving this strain to be a potential candidate for further studies. Endoglucanases, exoglucanases, and xylanase were achieved by using cheaply available agro-residues such as rice bran and sugar cane bagasse. The maximum levan production by $C$. cellulans MP1 was $14.8 \pm 1.2 \mathrm{~g} / \mathrm{l}$ after $20 \mathrm{~h}$ of cultivation in media containing $200 \mathrm{~g} / \mathrm{l}$ sucrose. To the best of our knowledge, the present study is the first genome-based analysis of a Cellulosimicrobium species which focuses on lignocellulosic enzymes and levan biosynthesis, illustrating Peer) reviewing PDF | (2021:03:58621:1:1:NEW 25 May 2021) 
that the $C$. cellulans MP1 has a great potential to be an efficient platform for basic research and industrial exploitation. 


\section{A genomic perspective on the potential of termite- 2 associated Cellulosimicrobium cellulans MP1 as 3 producer of plant biomass-acting enzymes and 4 exopolysaccharides}

5 Thi Hanh Nguyen $\mathrm{Vu}^{1,2 \dagger}$, Ngoc Tung Quach ${ }^{1,2 \dagger}$, Thi Thanh Xuan Dao ${ }^{3,4}$, Thanh Ha Le ${ }^{3 *}$, Phuong 6 Chi Le ${ }^{1}$, Tung Lam Nguyen ${ }^{3}$, Tung Lam Le ${ }^{1}$, Cao Cuong Ngo ${ }^{5}$, Hoang $\mathrm{Ha}^{1}$, Hoang Ha Chu ${ }^{1,2}$, 7 Quyet Tien Phi $^{1,2^{*}}$

$8{ }^{1}$ Institute of Biotechnology, Vietnam Academy of Science and Technology, Hanoi, Vietnam

$9{ }^{2}$ Graduate University of Science and Technology, Vietnam Academy of Science and Technology, 10 Hanoi, Vietnam

$11{ }^{3}$ School of Biotechnology and Food Technology, Hanoi University of Science and Technology, 12 Hanoi, Vietnam

$13{ }^{4}$ Vinh University, Vinh, Vietnam

$14{ }^{5}$ Vietnam - Russia Tropical Center

*: Corresponding Author:

1818 Hoang Quoc Viet, Hanoi 10000, Vietnam

19 Email address: tienpq@ibt.ac.vn

Thanh $\mathrm{Ha} \mathrm{Le}^{3}$

Email address: ha.lethanh@hust.edu.vn

\section{Abstract}

Background. Lignocellulose is a renewable and enormous biomass resource, which can be degraded efficiently by a range of cocktails of carbohydrate-active enzymes secreted by termite improving the conversion processes in the production of lignocellulosic-based products. Although various studies dedicated to the genus Cellulosimicrobium as gut symbiont, genetic potential related to plant biomass-acting enzymes and exopolysaccharides production has been fully untapped to date.

Methods. The cellulolytic bacterial strain MP1 was isolated from termite guts and identified to the species level by phenotypic, phylogenetic, and genomic analysis. To further explore genes related to cellulose and hemicellulose degradation, the draft genome of strain MP1 was obtained by using whole-genome sequencing, assembly, and annotation through the Illumina platform. to shed light on bacterial activities. 
39 Results. Among 65 isolates obtained, the strain MP1 was the most efficient cellulase producer with cellulase activity of $0.65 \pm 0.02 \mathrm{IU} / \mathrm{ml}$. The whole genome analysis depicted that strain MP1 consists of a circular chromosome that contained 4,580,223 bp with an average GC content of $73.9 \%$. The genome comprises 23 contigs including 67 rRNA genes, 3 tRNA genes, a single tmRNA gene, and 4,046 protein-coding sequences. In support of the phenotypic identification, the $16 \mathrm{~S}$ rRNA gene sequence, average nucleotide identity, and whole-genome-based taxonomic analysis demonstrated that the strain MP1 belongs to the species Cellulosimicrobium cellulans. A total of 30 genes related to the degradation of cellulases and hemicellulases were identified in the C. cellulans MP1 genome. Of note, the presence of sacC1-levB-sacC2-ls operon responsible for levan and levan-type fructooligosaccharides biosynthesis was detected in strain MP1 genome, but not with closely related $C$. cellulans strains, proving this strain to be a potential candidate for further studies. Endoglucanases, exoglucanases, and xylanase were achieved by using cheaply available agro-residues such as rice bran and sugar cane bagasse. The maximum levan production by $C$. cellulans MP 1 was $14.8 \pm 1.2 \mathrm{~g} / 1$ after $20 \mathrm{~h}$ of cultivation in media containing $200 \mathrm{~g} / 1$ sucrose. To the best of our knowledge, the present study is the first genome-based analysis of a Cellulosimicrobium species which focuses on lignocellulosic enzymes and levan biosynthesis, illustrating that the $C$. cellulans MP1 has a great potential to be an efficient platform for basic research and industrial exploitation.

Subject Genomics, Microbiology, Molecular Biology

Keywords Carbohydrate-active enzymes, Cellulosimicrobium cellulans, levan, lignocellulose, termite guts, whole-genome sequencing

61

\section{Introduction}

Termites are social insects contributing to nutrient recycling in terrestrial ecosystems and many vertebrate food chains (Wong et al. 2014). Termites utilize microbes in the hindgut to hydrolyze efficiently cellulose of wood and lignocellulosic materials, into more easily digested sugars and short-chain fatty acids (Ohkuma 2003; Pasari et al. 2019). As demonstrated previously, termites were not able to digest the lignocellulosic biomass, a mixture of cellulose, hemicellulose, lignin, and pectin completely in the absence of symbiotic microorganisms such as bacteria, archaea (Tokuda \& Watanabe 2007; Wong et al. 2014). Thus, termite gut served as a promising source of identifying novel cellulolytic enzymes as well as an excellent model for further investigating the symbiotic relationships between bacteria and their host.

Recently, bacterial symbionts are acquiring much attention from researchers over the world as potential sources for screening novel and highly efficient lignocellulose-degrading enzymes. They can be applied in many industries like biofuel, food, pulp and paper, and agriculture (Chutani \& Sharma 2016; Pandey et al. 2016). Species belonging to genus Bacillus Brevibacillus, Cellulomonas, Streptomyces, and Paenibacillus were well-studied as excellent cellulases, hemicellulases, xylanase and pectinases producers (Kamsani et al. 2016; Ohkuma 2003; Pasari et 
79 three different groups such as endoglucanase, exoglucanase, and $\beta$-glucosidase (Jäger \& Büchs 2012; Wi et al. 2015). Typical hemicellulases are arabinoxylanases, mannanase, and xylanases involved in hemicellulose decomposition (Dashtban et al. 2009). The whole-genome sequencing approach was used to promote rapid advances in the discovery of potent cellulase and hemicellulose enzymes. With regards to 20 identified CAZymes including 12 endoglucanases, 2 exoglucanases, and $6 \beta$-glucosidases, halophilic bacterium Parvularcula flava $\mathrm{NH} 6-79^{\mathrm{T}}$ serves as cellulolytic enzymes producer (Abdul Karim et al. 2020). Micromonospora sp. CP22 was reported to depolymerize the lignocellulosic biomass based on 63 cellulolytic and hemi-cellulolytic CAZymes found in the genome (Chen et al. 2020). The genome B. velezensis LC1 was shown to contain 31 genes involved in lignocellulose degradation, and some of these genes were highly induced in presence of bamboo shoot power ( $\mathrm{Li}$ et al. 2020). This finding is especially significant given that few genomes of termite gut symbiotic bacteria are available.

Levan has received increasing scientific attention due to its application in the pharmaceutical, industrial, and food fields (Belghith et al. 2012; Dahech et al. 2011; Yoo et al. 2004). Indeed, levan is mainly composed of $\beta-2,6$ polyfructan with extensive branching through $\beta-(2,1)$ linkages, that are mostly synthesized by bacterial enzymes (Gojgic-Cvijovic et al. 2019; Mardo et al. 2017). Japan, the US, and South Korea allowed food and pharmaceutical companies to manufacture levan as a functional food additive (Verspreet et al. 2015), while it is not commercially permitted in Europe (Mardo et al. 2017). Bacterial levan is synthesized in sucrose-rich environments through the action of levansucrase (EC 2.4.1.10) for energy reserve and biofilm formation (Shih et al. 2005). Under starvation conditions, accumulated levan was found to be converted into levan-type fructooligosaccharides (L-FOs) that are imported across the outer membrane (Gray et al. 2021). Until now, many bacteria were reported to produce levan such as Bacillus, Erwinia, Pseudomonas, Microbacterium, and Zymomonas (Gojgic-Cvijovic et al. 2019). The whole genome sequencing shed light on the full potential of levansucrase and levanse in levan-producing bacteria. As revealed in $B$. subtilis, $s a c B$ gene encoding for levansucrase catalyzes the synthesis of levan, which is then degraded mainly into levanbiose by the action of levanase such as YveA and YveB. In addition, the $s a c B-y v e B-y v e A$ levansucrase tricistronic operon is conserved across 12 complete genome sequences of $B$. subtilis (Dogsa et al. 2013). sacB gene was also found to be conserved in halophilic bacterium Halomonas smyrnensis AAD6R (Diken et al. 2015).

In previous studies, complete genome sequencing showed that genus Cellulosimicrobium is a rich source of glycosidases involved in plant-growth promoting and ginseng biotransformation 111 abilities (Eida et al. 2020; Zheng et al. 2017). To the best of our knowledge, genomic analysis of

112 Cellulosimicrobium has not been revealed to prove a better understanding of its genetic basis for 113 other applications. In this study, we report for the first time, the identification and detailed genomic 114 analysis of cellulose-degrading and levan-producing Cellulosimicrobium cellulans MP1 isolated 115 from the termite gut. These findings provided a scientific basis for the further employment of strain 116 MP1 and its potential genes in biotechnological processes.

\section{Materials \& Methods}




\section{Isolation of symbiotic cellulolytic bacteria}

120 Drywood termites (Cryptotermes domesticus) were collected from rotten tree trunks and bagasse 121 in Nghe An Province, Vietnam. Termites were surface-sterilized using $70 \%$ ethanol to remove 122 contamination and then washed with sterile distilled water. The head of each termite was removed 123 using forceps; the entire guts were removed, crushed with glass rods, and subsequently inoculated 124 into $1 \mathrm{ml}$ broth mineral medium $\mathrm{M} 1\left(\mathrm{NaNO}_{3} 2.5 \mathrm{~g} ; \mathrm{NaCl} 0.1 \mathrm{~g} ; \mathrm{KH}_{2} \mathrm{PO}_{4} 2 \mathrm{~g} ; \mathrm{MgSO}_{4} 0.2 \mathrm{~g}\right.$; $125 \mathrm{CaCl}_{2} \cdot 6 \mathrm{H}_{2} \mathrm{O} 0.1 \mathrm{~g}, \mathrm{pH} 7.0$ in a liter) containing $1 \%$ carboxymethylcellulose $(\mathrm{CMC})$ or filter paper 126 as a sole carbon source (Gupta et al. 2012). These cultures were incubated for 14 days in an 127 incubating sharker at $30^{\circ} \mathrm{C}$. To isolate the cellulolytic bacteria, the growing cultures were spread 128 on the $\mathrm{M} 1$ plate medium $\left(\mathrm{K}_{2} \mathrm{HPO}_{4} 1 \mathrm{~g} ; \mathrm{NaNO}_{3} 2.5 \mathrm{~g} ; \mathrm{KCl} 2 \mathrm{~g}\right.$; peptone $2 \mathrm{~g} ; \mathrm{MgSO}_{4} 0.5 \mathrm{~g} ; \mathrm{CMC}$ $12910 \mathrm{~g}$; agar $15 \mathrm{~g}$; pH 7.0 in a liter). All bacterial isolates were subsequently purified by re-streaking 130 on the M2 agar plate. Confirmation of the cellulolytic ability of pure isolates was performed on 131 the solid medium by covering the Petri dishes with Congo-red dye (Teather \& Wood 1982). The 132 colonies showing yellow-colored halo zones by Congo-red staining were considered as positive 133 cellulolytic bacteria and the clear zones were measured.

134

\section{Physiological, biochemical, and 16S rRNA sequencing analysis}

136 The shape and size of strain MP1 were determined by scanning electron microscope (SEM) JSM-

1375410 (JEOL, Tokyo, Japan). Gram staining was performed using the conventional methodology 138 and confirmed using the $\mathrm{KOH}$ test (Powers 1995). The effects of different conditions (ranges of $139 \mathrm{pH}, \mathrm{NaCl}$ concentration and temperature, carbon and nitrogen sources) on the growth were investigated as previously described (Kamlage 1996).

141 Genomic DNA for 16S rRNA gene sequencing was prepared by phenol-chloroform extraction.

142 The amplification of the 16S rRNA gene sequence of strain MP1 was performed by using the

143 universal primer pair 27F (5' -TAACACATGCAAGTCGAACG-3') and 1429R (5'144 GGTGTGACGGGCGGTGTGTA-3') (Phi et al. 2010). A sequence similarity search was carried 145 out using the BLAST program (http://blast.ncbi.nlm.nih.gov/Blast.cgi). The phylogenetic tree was 146 computed by using the neighbor-joining method with 1000 bootstrap in MEGA version 6.0 147 (Tamura et al. 2013). Numbers at nodes indicate percentages of 1000 bootstrap re-samplings and 148 Bifidobacterium bifidum DSM 20456 (S83624) was used as the outgroup branch. The 16S rDNA 149 gene sequence of strain MP1 was deposited onto the GenBank (NCBI) under accession number 150 MW534740.

151

152 Genome sequencing, de novo assembly, and annotation

153 For library construction, DNA was extracted from a pure culture of a single colony of strain MP1 154 using G-spin ${ }^{\mathrm{TM}}$ Total DNA Extraction Mini Kit according to the manufacturer's instructions. The 155 quantity and quality of extracted DNA were evaluated by electrophoresis in $0.6 \%(\mathrm{w} / \mathrm{v})$ agarose 156 gel and NanoDrop spectrophotometer 2000 (Thermo Scientific) in order to construct a paired-end 157 library. The constructed genome library was then sequenced using the Illumina platform (Illumina, 158 California, USA). Quality control and read trimming were conducted using FastQC version 0.11.5 
159 (http://www.bioinformatics.babraham.ac.uk/projects/fastqc) and Trimmomatic version 0.36 160 (Bolger et al. 2014). The de novo genome assembly was made with SPAdes v.3.13 (Bankevich et 161 al. 2012), which was then analyzed for its completeness using the Benchmarking Universal Single162 Copy Orthologous (BUSCO) version 3 (https://gitlab.com/ezlab/busco).

163 The draft genome assembled into contigs was annotated using Prokaryotic Genomes 164 Annotation Pipeline (PGAP; http://www.ncbi.nlm.nih.gov/genome/annotation_prok/) at NCBI. In 165 addition, the CRISPRCasFinder was used to identify putative CRISPR loci and Cas cluster (Grissa 166 et al. 2007). Orthologous genes and Gene ontology (GO) were analyzed using clusters of 167 orthologous genes (COGs) (Galperin et al. 2015) and InterProScan 5 (Jones et al. 2014), 168 respectively. Virulence factors-encoding genes were identified using the Pathosystems Resource 169 Integration Center (PATRIC) platform (Wattam et al. 2017). The graphical map of the circular 170 genome was also generated using PATRIC. The draft genome sequence was deposited in the NCBI 171 GenBank database under accession number: JAFGYF000000000.

172 Analysis of whole-genome similarity

To classify strain MP1 at the species level, whole-genome similarity including average nucleotide identity (ANI) calculation and digital DNA-DNA hybridization (dDDH) was performed. The ANI was calculated using the orthologous average nucleotide identity (OrthoANI) (Lee et al. 2016). The MP1 genome sequence data was uploaded to the Type (Strain) Genome Server (TYGS) for a whole-genome-based taxonomic analysis (https://tygs.dsmz.de). In silico dDDH and the branch lengths were and the Genome BLAST Distance Phylogeneny evaluated using Genome-to-Genome Distance Calculator (GGDC) (Meier-Kolthoff et al. 2013).

\section{Comparative genomics and prediction of Carbohydrate-active enzyme}

184

A genome-wide comparison of COGs between the assembled genome of Cellulosimicrobium cellulans MP1 and three other C. cellulans available in GenBank, including J36 (NZ_QUMZ01000000.1), was implemented using the OrthoVenn web server with default parameters (E-value 1e-5 and inflation value 1.5) (Wang et al. 2015). The putative genes encoding CAZymes in the comparative genomes were predicted using the dbCAN2 meta server and classified by DIAMOND, HMMER, and Hotpep via CAZy and dbCAN databases, respectively. The top hits with e-value $<1 \mathrm{E}-17$, minimum homology rate $>50 \%$, and coverage $>45 \%$ were considered to be homologs.

\section{Determination of extracellular enzymatic activities}

To verify the production of endoglucanase, $C$. cellulans MP1 was cultivated in the TN medium (rice bran $20 \mathrm{~g}$; soya peptone $10 \mathrm{~g}$, casein $10 \mathrm{~g}, \mathrm{NaCl} 1 \mathrm{~g}, \mathrm{pH} 7.0$ in a liter) at $37^{\circ} \mathrm{C}$ with vigorous sharking. At different time intervals, samples were taken, followed by centrifugation at $4^{\circ} \mathrm{C}$, $12,000 \mathrm{rpm}$ for $10 \mathrm{~min}$ to remove bacterial cells and insoluble materials from the culture broth. About $0.5 \mathrm{ml}$ crude enzyme solution was added into $0.5 \mathrm{ml}$ of $0.05 \mathrm{M}$ sodium phosphate, $\mathrm{pH} 7.0$ buffer containing $1 \%$ of $\mathrm{CMC}$. The mixture was then incubated at $30^{\circ} \mathrm{C}$ for $30 \mathrm{~min}$, which was 
200

201

202

203

204

205

206

207

208

209

210

211

212

213

214

215

216

217

218

219

220

221

222

223

224

225

226

227

228

229

230

231

232

233

234

235

236

237

238

239

stopped by adding $1 \mathrm{ml}$ of 3,5'-dinitrosalicylic acid (DNS) reagent followed by boiling the reaction mixture at $100^{\circ} \mathrm{C}$ for $5 \mathrm{~min}$ (Miller 1959). As for xylanase production, strain MP1 was cultivated on $\mathrm{M} 1$ medium $\left(\mathrm{K}_{2} \mathrm{HPO}_{4} 1 \mathrm{~g} ; \mathrm{KCl} 2 \mathrm{~g} ; \mathrm{NH}_{4} \mathrm{Cl} 2.5 \mathrm{~g}\right.$; yeast extract $2 \mathrm{~g}, \mathrm{MgSO}_{4} 0.5 \mathrm{~g}$, sugar cane bagasse $5 \mathrm{~g}, \mathrm{pH} 7.0$ in a liter) at $37^{\circ} \mathrm{C}$ for 4 days. At different time intervals, culture was centrifuged at $4^{\circ} \mathrm{C}, 12,000 \mathrm{rpm}$ for $10 \mathrm{~min}$ to obtain the crude enzyme. About $0.5 \mathrm{ml}$ crude enzyme was mixed with $0.5 \mathrm{ml}$ of the substrate solution and incubated at $50^{\circ} \mathrm{C}$ for $5 \mathrm{~min}$, followed by adding $1 \mathrm{ml}$ DNS reagent. Xylanase was assayed using $1 \%$ birchwood xylan solution in acetate buffer, $\mathrm{pH} 5.0$ as the substrate (Bailey et al. 1992). To quantify pectinase activity, the $\mathrm{M} 2$ medium $\left(\mathrm{NH}_{4} \mathrm{Cl} 2.5 \mathrm{~g}\right.$; $\mathrm{K}_{2} \mathrm{HPO}_{4} 1 \mathrm{~g} ; \mathrm{MgSO}_{4} 0.5 \mathrm{~g} ; \mathrm{KCl} 2 \mathrm{~g}$; yeast extract $2 \mathrm{~g}$, rice bran $10 \mathrm{~g}$; lactose $10 \mathrm{~g} ; \mathrm{pH} 7.0$ in a liter) was used. The pectinase assay was performed at $40^{\circ} \mathrm{C}$ for $30 \mathrm{~min}$ as described previously (Mercimek Takc1 \& Turkmen 2016). The quantitative enzyme assays of endoglucanase, xylanase, and pectinase were performed according to standard IUPAC procedures and expressed as international units (IU) (Ghose 1987). One unit (IU) of enzymatic activity is defined as the amount of enzyme that releases $1 \mu \mathrm{mol}$ reducing sugars per $\mathrm{ml}$ fermentation supernatant per minute under assay conditions.

\section{Levan determination}

To test the ability to synthesize levan, the $C$. cellulans MP1 was cultured overnight in batch culture medium (yeast extract $7 \mathrm{~g},\left(\mathrm{NH}_{4}\right)_{2} \mathrm{SO}_{4} 1.5 \mathrm{~g}, \mathrm{~K}_{2} \mathrm{HPO}_{4} 2.5 \mathrm{~g}, \mathrm{pH} 7.0$ in a liter) at $37^{\circ} \mathrm{C}$ under vigorous agitation. The overnight culture was transferred to a new batch culture medium supplemented with 100 and $200 \mathrm{~g} / 1$ sucrose and adjusted to an optical density at $600 \mathrm{~nm}$ of 0.1 . The culture was centrifuged at $10,000 \mathrm{rpm}$ for $10 \mathrm{~min}$ at different time points. Cell-free supernatant was used to determine levan produced during fermentation (Gojgic-Cvijovic et al. 2019). Levan was harvested by adding three volumes of ice-cold ethanol. The mixture was kept at $4^{\circ} \mathrm{C}$ for $12 \mathrm{~h}$, centrifuged at $12,000 \mathrm{rpm}$ at $4{ }^{\circ} \mathrm{C}$ for $20 \mathrm{~min}$, and washed with $75 \%$ ethanol to remove the residual sugars. The obtained precipitate was hydrolyzed with $0.1 \mathrm{M} \mathrm{HCl}$ at $100^{\circ} \mathrm{C}$ for $1 \mathrm{~h}$. After neutralizing with $2 \mathrm{M} \mathrm{NaOH}$, levan content was determined according to Somogyi and Nelson (Somogyi 1945).

\section{Results}

\section{Cellulose-degrading potential and identification of the strain MP1}

Of the 65 isolates able to grow on CMC plates as the sole carbon source, a total of 8 bacterial isolates produced variable zones of CMC clearance after Congo-red staining. Among those, MP1 was selected due to showing the maximum zone of clearance $(9 \pm 1,1 \mathrm{~mm})$. In support of this result, enzyme assays for cellulase activity on CMC and filter paper were found to be the highest for MP1 with $0.66 \pm 0.15 \mathrm{IU} / \mathrm{ml}$ after $48 \mathrm{~h}$ and $0.33 \pm 0.05 \mathrm{FPU} / \mathrm{ml}$ after 72 hours of cultivation, respectively (Tab. S1). These results indicated that isolate MP1 is a potent cellulolytic bacterium for further study.

The phenotypic examinations indicated that MP1 grew well on LB agar after 2 days incubation at $37^{\circ} \mathrm{C}$, producing colonies that were circular, smooth, convex, and pale yellow in colour. As 
240 viewed under a scanning electron microscope, isolate MP1 revealed that cells were Gram-positive, 241 non-spore-forming rods, and nonmotile. The strain MP1 could utilize D-galactose, D-sucrose, D242 raffinose, and amygdalin as sole carbon and energy (Tab. S2). It gave a positive test for catalase, 243 starch hydrolysis, $\beta$-galactosidase, and nitrate reduction, whereas negative for oxidase, gelatinase, 244 urease, indole, $\mathrm{H}_{2} \mathrm{~S}$, acetoin. The 16S rDNA gene sequence of MP1 was aligned with the similar 245 nucleotide sequences in the GenBank database in which a phylogenetic tree was then constructed. 246 The neighbor-joining phylogenetic tree showed the close relationship between MP1 and related 247 Cellulosimicrobium species and the highest homology to Cellulosimicrobium cellulans DSM 24843879 (99.5\%) and Cellulosimicrobium funkei A153 (99.6\%) (Fig. 1). Further, the OrthoANI 249 software was performed to determine the OrthoANI value between isolate MP1 and five closely 250 related Cellulosimicrobium species. It revealed that MP1 shared high similarity to C. cellulans DSM 43879 (88.71\%), C. funkei JCM 14302 (91.35\%), and C. funkei JCM NRBC 104118 (91.35\%), and low nucleotide similarity was observed with Promicromonospora sukumoe SAI064 that were out of distinct sub-clade (Fig. 2A). This result confirmed that this strain was not considered to be a novel species.

To make identification more accurate at the species level, the whole-genome-based taxonomic analysis conducted by the Type Strain Genome Server (TYGS) platform suggested that Cellulosimicrobium sp. MP1 was closest to C. cellulans DSM 43879 with digital DNA-DNA hybridization $(\mathrm{dDDH})$ values and differences in guanine-cytosine $(\mathrm{GC})$ content of $57.5 \%$ (formula $\mathrm{d}_{6}$ ) and $0.56 \%$, respectively (Fig. 2B). As shown previously, the differences between $C$. funkei and C. cellulans in phenotypic characteristics are motility and ability to utilize raffinose (Hamada et al. 2016; Yoon et al. 2007). Based on the phenotypic characteristics and genome-wide comparison, this strain was identified as Cellulosimicrobium cellulans MP1. This bacterium was deposited at VAST-Culture Collection of Microorganisms (VCCM) with the accession number VCCM 14150.

\section{Genome sequence and general features of the C. cellulans strain MP1}

Briefly, the standard short insert library yielded 443,986,169 bases resulting in 4,487,842 mapped reads with about 92.2-fold sequencing depth. The draft genome of strain MP1 (4,580,223 bp with GC content of $73.9 \%$ ) was assembled into a ring chromosome, comprising of 23 contigs and no plasmid was detected (Fig. 3). The genome was predicted to have 4,088 genes assigned for 3,964 protein-coding sequences (CDS), 61 rRNA sequences, 55 tRNA sequences, 3 ncRNA sequences (Table 1). Moreover, a total of three virulence factors present in $C$. cellulans MP1 included dihydroxy-acid dehydratase, CarD-like transcriptional factor, and two calmodulin-like proteins (Fig. 3).

A total of $79.5 \%(3,216$ out of 4,046) of the protein-coding sequences were assigned to 21 out of $25 \mathrm{COG}$ functional categories (Fig. 4A). Transcription (K: 365 protein-coding sequences),

276

277 carbohydrate transport and metabolism (G: 307), amino acid transport and metabolism (E: 224), energy production and conversion (C: 199), and inorganic ion transport and metabolism (P: 180)

278 were found to be the largest categories. By contrast, the least represent groups included cell cycle 
279

280

281

282

283

284

285

286

287

288

289

290

291

292

293

294

295

296

297

298

299

300

301

302

303

304

305

306

307

308

309

310

311

312

313

314

315

316

317

318

control, cell division, chromosome partitioning (D: 33), chromatin structure and dynamics (B: 2), and cell motility (N: 1)

$\mathrm{GO}$ analysis was used to provide a deeper understanding of the functional catalogs of strain MP1. A total of 3,165 genes were assigned to 43 subclasses, including 13 subclasses of the cellular component (CC) class, 10 subclasses of the molecular function (MF) class, and 20 subclasses of the biological process (BP) class (Fig. 4B). In detail, the CC class occupied the most genes (1638 genes; $45.3 \%$ ), followed by the BP (1424 genes; 39.4\%), and MF (553 genes; $15.3 \%$ ) class. The most abundant pathways were cell (GO:0005623; 508 genes), cell part (GO:0044464; 508 genes), and membrane (GO:0016020; 340 genes), which could be considered as the main functional groups of genes belonging to the $\mathrm{CC}$ class. Within the BP class, the three most prevalent molecular functions were metabolic process (GO:0008152; 378 genes), cellular process (GO:0009987; 379 genes), and growth (GO:0040007; 281 genes) (Fig. 4B). Among all subclasses belonging to the MF class, catalytic activity (GO:0003824) and binding (GO:0005488) contributed the most genes, with 311 and 176, respectively.

\section{Genome-wide comparison of COGs and Carbohydrate-active enzymes}

Given that microbial evolution is due to vertical descent from a single ancestral gene leading to orthologous genes in different species, it is necessary to explore gene function, gene structure, and molecular evolution by using a genome-wide comparison of COGs in different strains. The COGs of $C$. cellulans MP1 were compared with four other strains, including J36, LMG16121, and ZKA48. It showed that C. cellulans MP1 comprised of 3405 COGs and 794 singletons. $C$. cellulans J36 and ZKA48 included 3604 and 3605 COGs, respectively, whereas the lowest COGs were observed in LMG16121 (Fig. 5A). Surprisingly, strain MP1 had the largest number of singletons $(n=794)$. Venn diagram denoted that a total of 2,539 COGs were commonly shared by all four strains of $C$. cellulans. Among the unique COGs observed in all strains, strain MP1 had the largest number of 20 (Fig. 5A). To support this result, the REALPHY phylogeny builder web tool was used to compare $C$. cellulans genomes. A maximum-likelihood phylogenetic tree showed that MP1 and LMG16121 formed a monophyletic clade, suggesting a strong evolutionary relationship (Fig. S1).

Using dbCAN 2 meta server, the putative genes encoded for CAZymes present in C. cellulans MP1 were screened to find out the genes responsible for cellulose and hemicellulose degradation. After removing the sequences that did not meet the filtering criteria, a total of 195 predicted CAZymes was identified corresponding to $4.8 \%$ of the total of 3,216 protein-coding sequences observed in this strain. Glycoside hydrolases (GHs) involved in the degradation of the most plant biomass such as cellulose and hemicellulose were predicted to be the most abundant subfamily with 99 enzymes. Next, 39 glycosyltransferases (GTs), 37 carbohydrate-binding modules (CBMs), 11 carbohydrate esterases (CEs), 6 enzymes with auxiliary activities (AAs), and 3 polysaccharide lyases (PLs) were detected (Fig. 5B).

The genome of $C$. cellulans MP1 was compared to closely related C. cellulans such as $C$. cellulans J36, C. cellulans LMG16121, C. cellulans ZKA48. Generally, C. cellulans MP1 had 
319 significantly more CAZyme domains found than other C. cellulans strains. Despite forming a 320 monophyletic clade with strain LMG16121, MP1 was 56 CAZyme domains higher than

321

322

323

324

325

326

327

328

329

330

331

332

333

334

335

336

337

338

339

340

341

342

343

344

345

346

347

348

349

350

351

352

353

354

355

356

357 LMG16121. Meanwhile, with the exception of LMG16121, the family numbers of GT, CBM, and AA family numbers were the same in all compared strains, suggesting the coexistence of these genes in breaking down cellulosic biomass (Fig. 5B).

\section{Mining of plant biomass-acting enzymes in $C$. cellulans MP1 gene pool}

CAZyme analysis suggested that 30 cellulose-related sequences were detected in the genome of C. cellulans MP1. The major families related to the degradation of cellulose are GH6, GH9, GH48, GH10, GH16, GH1, GH3, GH13, and GH64. Based on the annotation, 5 endoglucanases (two GH6 and three GH9), 3 exoglucanases (GH6, GH10, and GH48), and lichenase (GH16) were revealed in the genome of strain MP1 (Table 2). A total of five out of the eight annotated endoglucanases and exoglucanases (orf_454, orf_1616, orf_3244, orf_1607, orf_1611) contained a CBM2 domain appended to them, which have been known to bind to crystalline cellulose, insoluble chitin, and xylan (McLean et al. 2002). CBM2 was the major CBMs present in the genome of strain MP1. In the $\beta$-glucosidases family, three GH1 and six GH3 were considered as other important members for cellulose degradation and three GH13 had $\alpha$-glucosidase activity. It is interesting to note that two pectate lyases such as PL4 (orf_102) and PL1 (orf_1326) belonging to the large class of PL were identified (Table 2). Given that pectin is involved in providing structural support for plant such as cell walls, wall integrity, and cell-cell cohesion, pectate lyases (EC 4.2.2.2) belonging to pectinase catalyze the eliminative cleavage of $\alpha-1,4$-glycosidic bonds between $\mathrm{C}_{4}$ and $\mathrm{C}_{5}$ of pectin or pectic acid, producing unsaturated methyloligogalacturonates (Abbott et al. 2010; Hugouvieux-Cotte-Pattat et al. 2014). Pectate lyases are important symbiotic bacteria through facilitating their growth in presence of highly pectinolytic bacteria and under pectin-rich environments (Hugouvieux-Cotte-Pattat et al. 2014).

For hemicellulose degrading genes mining, a total of 21 annotated proteins were deduced to involve in hemicellulose degradation. The major families responsible for the breakdown of hemicellulose were GH43, GH31, GH127, GH51, GH10, GH36, and GH4, and the total number of enzymes, including all families, was 21 (Table 2). Among them, the most abundant enzymes were attributed to GH43 (9 enzymes), followed by GH124 (3 enzymes) and GH31 (2 enzymes), indicating that strain MP1 might have great potentials for degradation of hemicellulosic backbones or debranding hemicellulose. Hemicellulose-related genes were predicted as mannan endo-1,4- $\beta$ mannosidase, arabinoxylan arabinofuranohydrolase, $\alpha$-xylosidase, $\alpha$-L-arabinofuranosidase, $\beta$-Larabinofuranosidase, endo-1,4- $\beta$-xylanase, $\alpha$-galactosidase, and bifunctional $\beta$-xylosidase $/ \alpha$ arabinosidase (Table 2). Only two enzymes, mannan endo-1,4- $\beta$-mannosidase and $\alpha$-galactosidase, have the ability to hydrolyse parts of mannan, the second major component in hemicellulose. Two endo-1,4- $\beta$-xylanase (orf_100 and orf_3772) and one bifunctional $\beta$-xylosidase $/ \alpha$-arabinosidase (orf_3988) were coupled with either CBM2 or CBM9. Surprisingly, genes encoding arabinofuranosidase (orf_3999, orf_4000, orf_4001 and orf_4002), arabinoxylan arabinofuranohydrolase (orf_4003), and bifunctional $\beta$-xylosidase/ $\alpha$-arabinosidase (orf_4004) are 
358

359

360

361

362

363

364

365

366

367

368

369

370

371

372

373

374

375

376

377

378

379

380

381

382

383

384

385

386

387

388

389

390

391

392

393

394

395

396

clustered in an operon. However, AA enzymes were not found to be related to cellulose and hemicellulose degradation.

To confirm the ability to produce endoglucanase, xylanase, and pectinase of strain MP1, the quantitative enzyme assay was monitored across different incubation periods $(24 \mathrm{~h}, 48 \mathrm{~h}, 72 \mathrm{~h}, 96$ h, $120 \mathrm{~h}$ ) (Fig. 6). Using rice bran as an inducible substrate for endoglucanase production, the lowest endoglucanase activity of $0.15 \pm 0.01 \mathrm{IU} / \mathrm{ml}$ was observed at $24 \mathrm{~h}$, followed by an increase of activity within $48 \mathrm{~h}$ to $96 \mathrm{~h}$. The highest endoglucanase production of about $3.17 \pm 0.10 \mathrm{IU} / \mathrm{ml}$ was achieved after $72 \mathrm{~h}$ of incubation. The reduced activity of endoglucanase was notified as 1.40 $\pm 0.17 \mathrm{IU} / \mathrm{ml}$ at $120 \mathrm{~h}$. Xylanase activity of strain MP1 was monitored on M1 medium supplemented with sugar cane bagasse at $37^{\circ} \mathrm{C}$ for $120 \mathrm{~h}$. The result was a steep increase within 0 to $72 \mathrm{~h}$ of incubation times. The highest enzyme production was recorded during the stationary phase reaching maximum $(1.84 \pm 0.08 \mathrm{IU} / \mathrm{ml})$ at $96 \mathrm{~h}$, followed by a slight decrease after $120 \mathrm{~h}$ (Fig. 6C). Regarding to pectinase, the maximum pectinase yield was $0.16 \pm 0.01 \mathrm{IU} / \mathrm{ml}$ after $48 \mathrm{~h}$ of incubation. Increasing incubation time was subjected to a significant decrease of pectinase activity. Despite the fact that a number of studies involved in the yields of endoglucanase, xylanase, and pectinase have been performed, it is hard to compare due to the effect of production conditions, substrate and assay conditions, and the way of defining the units.

\section{Levan exopolysaccharide biosynthesis and degradation}

Apart from cellulose-related genes, we were interested in the gene encoding for levansucrase (orf_22) since the ability of the genus Cellulosimicrobium to produce levan has not been studied yet. Levansucrase (EC 2.4.1.10) belonging to GH32 participates in synthesizing levan using high sucrose concentration as the main substrate (Raga-Carbajal et al. 2018). The C. cellulans MP1 $l s$ gene consists of 1,851 nucleotides encoding a protein of 616 amino acids with the predicted molecular mass of $66.6 \mathrm{kDa}$. Alignment of the amino acid sequence of $C$. cellulans MP1 Ls shows the highest level of identity with Gluconacetobacter diazotrophicus (61\%) and Microbacterium saccharophilum (58\%) (Fig. S2). In addition, levansucrase is clustered alongside levanbioseproducing levanase (levB-orf_20) and levanases (sacC1-orf_19 and sacC2-orf_21) in an operon (Fig. 7A). This result suggested that levan produced by $C$. cellulans MP1 may be hydrolyzed into L-FOs such as levanbiose and levanases. It is noteworthy that the $s a c C 1-l e v B-s a c C 2-l s$ operon was not present in the compared C. cellulans strains

The levan production in media with different initial sucrose concentrations was monitored as shown in Figure 7B. Levan production depended on cultivation time and sucrose concentration. In the medium with $100 \mathrm{~g} / 1$ sucrose, the maximum levan concentration was achieved at $20 \mathrm{~h}(9.9 \pm$ $0.11 \mathrm{~g} / \mathrm{l})$, followed by a significant decrease after $24 \mathrm{~h}(5.5 \pm 0.02 \mathrm{~g} / \mathrm{l})$. When sucrose concentration was increased to $200 \mathrm{~g} / \mathrm{l}$, the highest yield of levan was $14.8 \pm 1.2$ at $20 \mathrm{~h}$. It was noteworthy that levan was accumulated in the stationary phase.

\section{Discussion}


397 More recently, the exploitation of new plant biomass-acting enzymes and exopolysaccharides with 398 special characteristics has become important since the technological use of agro-industrial residues 399 is increasing. They are exploited favourably in food, paper, cosmetic and pharmaceutical industries 400 (Angelin \& Kavitha 2020; Walia et al. 2017; Zheng et al. 2017). In this context, termites are

401

402

403

404

405

406

407

408

409

410

411

412

413

414

415

416

417

418

419

420

421

422

423

424

425

426

427

428

429

430

431

432

433

434

435

436 thought to rely on the gut microbiome to digest wood and other types of plant biomass consisting mainly of cellulose as well as hemicellulose (Calusinska et al. 2020), making them an ideal source to search for new enzymes. Many cellulolytic bacteria from termite have been extensively investigated in the past, despite difficulties in isolation and cultivation (Kamsani et al. 2016). However, despite the use of high-throughput next-generation sequencing, potent biomass-acting enzymes have yet to be revealed. Our work is the first genome analysis systematically elucidating enzymes related to the decomposition of cellulose and hemicellulose and levan production of termite-associated $C$. cellulans. The findings provide valuable genome information for biotechnological applications.

Despite having potential in many fields, the genus Cellulosimicrobium remains poorly investigated. To date, the genus Cellulosimicrobium consists 7 species (six validly and one nonvalidly published names): C. variabile (Bakalidou et al. 2002), C. funkei (Brown et al. 2006), C. cellulans (Schumann et al. 2001), C. terreum (Yoon et al. 2007), C. marium (Hamada et al. 2016), C. aquatile (Sultanpuram et al. 2015), and C. arenosum (Oh et al. 2018). Only C. variabile was reportedly isolated from the hindgut of termites (Qin et al. 2018; Sharma et al. 2016). Since $C$. cellulans MP1 produced highly active cellulolytic activity on CMC and filter paper, we subsequently analyzed its whole genome for the presence of lignocellulose-degrading CAZymes. Of note, the genome possesses 17 cellulolytic and 21 hemicellulolytic enzymes, in which a total of 11 enzymes featuring CBM domains (CBM2, CBM4, CBM6, CBM9, CBM35) were found. CBM domains play an important role in enhancing the substrate-binding capability of the enzymes, and some CBMs are able to enhance the thermostability of the enzyme (Gilbert et al. 2013). CBM2 binds to various GH families including GH6 (orf_454, orf_3244), GH9 (orf_1616), GH10 (orf_1000, orf_1611), GH43 (orf_3988), and GH48 (orf_1607), which indicates the ability of these enzymes to bind to and support catalytic domains to hydrolyze crystalline cellulose and xylan. CBM9 domain was found only in endo-1,4- $\beta$-xylanase (orf_3772), which is responsible mainly for attacking the xylan backbone and is similar to Clostridium stercorarium Xyn10B and Thermotoga maritima Xyn10A (Lee \& Lee 2014). By contrast, endo-1,4- $\beta$-xylanase (orf_2117) had no CBM domain, indicating that other substrate-binding regions might replace the function of CBM. The detection of endoglucanase, exoglucanase, and xylanase activities is in agreement with the presence of the aforementioned genes. It is interesting to note that the strain MP1 cultivated in LB medium containing $0.5 \% \mathrm{CMC}$ had the lowest endoglucanase but activity of both enzymes increased at least 5.7 fold in TM3 medium supplemented with $2 \%$ rice bran, a low-cost agroresidue (Table S3). This result was considered as a promising strategy for reducing the cost of enzyme production and increasing enzyme efficiency.

Pectate trisaccharide-lyase (orf_102) and pectate lyase (orf_1326), which are involved in plant tissue maceration and modification of the cell wall structure (Atanasova et al. 2018), were 
437 identified based on the genomic analysis of strain MP1. Due to the ability to cleave pectin using a $438 \beta$-elimination mechanism, pectate lyases are produced either by bacteria living in close proximity with plants or by symbiotic gut bacteria (Biz et al. 2014; Jayani et al. 2005). Pectate lyases are important enzymes for industrial applications such as the beverage industry, pulp processing, waste treatment, leading to increasing attention of researchers over the world (Jayani et al. 2005; Zhao et al. 2018). Despite 72 genome sequences available at the time of writing and an array of extracellular enzymes found in Cellulosimicrobium, pectate lyases have not been identified yet. $C$. cellulans MP1 seemed to have acquired 2 different pectate lyases to establish itself in the termite gut. Additionally, pectinase produced activity of strain MP1 was low activity due to unoptimized medium. The production of pectinase can be optimized by using the response surface methodology as well as the recombinant enzyme, which is an interesting subject for further studies.

Interestingly, the presence of genes related to the levan exopolysaccharide in the genome of $C$. cellulans MP1 was predictable. Levan is one of the two main types of fructan biopolymers, produced from sucrose through the action of levansucrase (GH68) (Feng et al. 2015). Many studies showed that the GH68 is present in a number of genera, including Gluconobacter, Gluconacetobacter, Komagataeibacter, Asaia, Neoasaia, Bacillus, and Kozakia (Jakob et al. 2019); however, it has not been reported in the genus Cellulosimicrobium. Our finding revealed that the $s a c C 1-l e v B-s a c C 2-l s$ operon is not conserved across well-studied bacteria and that the $l s$ gene is encoded for active levansucrase, catalyzing the synthesis of higher-molecular-weight levan in presence of sucrose, which may serve as carbon storage for C. cellulans MP1. The molecules are hydrolyzed to L-FOs by levan-degrading enzymes including sacC12 and levB (Fig. 7C). Some studies indicate that levanase LevB hydrolyzes levan to generate levanbiose predominantly and $\mathrm{SacC}$ is reported to be active against levan and inulin leading to the formation of free fructose (Débarbouillé et al. 1991; Raga-Carbajal et al. 2018). In B. subtilis, anti-terminator, SacY is phosphorylated in presence of the excess sucrose, resulting in upregulation of conserved levansucrase $s a c B$ and two endolevanase yve $A B$ (Pereira et al. 2001). Another study demonstrated that activation of $s a c B$ also is regulated by pleiotropic regulatory genes $\operatorname{deg} S / \operatorname{deg} U, \operatorname{deg} Q$ and $\operatorname{deg} R$ (Débarbouillé et al. 1991). While no apparent homologs of SacY have been identified in the chromosome of strain MP1, 4 transcriptional factors $\operatorname{deg} A$ (orf_114, orf_207, orf_1005, orf_2448) and $\operatorname{deg} U$ (orf_296, orf_527, orf_1182, orf_2409) are present. Known that deletion of sacC in Zymomonas mobilis enhanced levan production $15.5 \mathrm{~g} / \mathrm{L}$ to $21.2 \mathrm{~g} / \mathrm{L}$ (Senthilkumar et al. 2004), further investigation on the regulation mechanisms of this operon is an interesting subject for improving levan production.

Interestingly, Ls shares the 2 conserved cysteines (at positions 383 and 439) and an overall sequence identity of $57-62 \%$ with orthologs of gram-negative bacteria such as Microbacterium saccharophilum, Burkholderia vietnamiensis, Gluconacetobacter diazotrophicus (Fig. S2). This result was in contrast to most gram-positive levansucrases that lack a pair of conserved cysteine residues (Jakob et al. 2019). In G. diazotrophicus levansucrase, Cys339-Cys395 intramolecular 475 disulfide bond plays an important role in protein folding and stability. Serin substitution for either 476 Cys339 or Cys395 abolished sucrose hydrolysis activity and levan-forming activity via preventing 
477 the extended loop between $\beta$-strands IIIB and IIIC with the insertion located between blades III 478 and IV (Martínez-Fleites et al. 2005). Further crystal structure analysis is required to reveal the 479 conformational changes of $C$. cellulans Ls upon reduction and oxidation conditions.

480

\section{Conclusions}

482 This study highlighted the ability of strain MP1 to degrade cellulose and hemicellulose and 483 produce levan. Out of 65 isolated termite gut symbiotic bacteria, isolate MP1, identified as $C$. 484 cellulans, exhibited the highest specific cellulase activity. The genome of C. cellulans MP1 is one 485 of 17 genomes of $C$. cellulans that are released onto the NCBI genome database, but it is the first 486 sequence that has been reported in detail from a biotechnological perspective. Both genomic and 487 experimental evidence proved that $C$. cellulans MP1 possesses 30 cellulose and 21 hemicellulose488 related sequences, which were functionally redundant for endoglucanases, endoxylanase, $\beta$ glucosidases, xylanase, $\beta$-xylosidases, arabinofuranosidase, and pectate lyase. Moreover, sacCllevB-sacC2-ls operon involved in levan and L-FOs production was pronounced for the first time, which could be a selective advantage during host-adaptation and colonization. These findings not only enrich the genome database but also provide a valuable source of information to continue research into the potential applications of $C$. cellulans MP1, including its possible use in the biofuel, pulp and paper, and pharmaceutical industries.

\section{Additional Information and Declarations}

498

\section{Competing Interests}

499

500

The authors declare there are no competing interests.

\section{Author Contributions}

502 Thi Hanh Nguyen Vu, Ngoc Tung Quach, and Thi Thanh Xuan Dao conceived and designed the experiments, prepared figures and/or tables, authored or reviewed drafts of the paper, and approved 504 the final draft.

505 Thanh Ha Le, Tung Lam Nguyen, Tung Lam Le, and Phuong Chi Le performed the experiments, 506 prepared figures and/or tables, and approved the final draft.

507 Hoang Ha and Cao Cuong Ngo authored or reviewed drafts of the paper, and approved the final 508 draft.

509 Quyet Tien Phi and Hoang Ha Chu conceived and designed the experiments, prepared figures 510 and/or tables, authored or reviewed drafts of the paper, and approved the final draft.

511

512 Data Availability

513 The following information was supplied regarding data availability:

514

515 The 16S rDNA and genome sequence described here are accessible via GenBank: MW534740 and 516 JAFGYF000000000. 
517

518 Raw data are available in Tables S1-S3.

519

520

521

522

523

524

525

526

527

528

529

530

531

532

533

534

535

536

537

538

539

540

541

542

543

544

545

546

547

548

549

550

551

552

553

554

555

556

\section{Funding} (VAST) under Grant number: NVCC 08.03/21-21 preparation of the manuscript.

\section{Acknowledgements} manuscript.

\section{References} 01967-z 10.1016/j.ijbiomac.2020.06.190 1656(92)90074-J

This study was financially supported by the Vietnam Academy of Science and Technology

The funders had no role in study design, data collection, and analysis, decision to publish, or

The authors would like to thank the support of VAST - Culture Collection of Microorganisms, Institute of Biotechnology, Vietnam Academy of Science and Technology (www.vccm.vast.vn). We are grateful to Emerson Addison, Central Michigan University for critically reading the

Abbott DW, Gilbert HJ, and Boraston AB. 2010. The active site of oligogalacturonate lyase provides unique insights into cytoplasmic oligogalacturonate beta-elimination. Journal of Biological Chemistry 285:39029-39038. 10.1074/jbc.M110.153981

Abdul Karim MH, Lam MQ, Chen SJ, Yahya A, Shahir S, Shamsir MS, and Chong CS. 2020. Draft genome sequence of Parvularcula flava strain NH6-79 T, revealing its role as a cellulolytic enzymes producer. Arch Microbiol 202:2591-2597. 10.1007/s00203-020-

Angelin J, and Kavitha M. 2020. Exopolysaccharides from probiotic bacteria and their health potential. International Journal of Biological Macromolecules 162:853-865.

Atanasova L, Dubey M, Grujić M, Gudmundsson M, Lorenz C, Sandgren M, Kubicek CP, Jensen DF, and Karlsson M. 2018. Evolution and functional characterization of pectate lyase PEL12, a member of a highly expanded Clonostachys rosea polysaccharide lyase 1 family. BMC Microbiology 18:178. 10.1186/s12866-018-1310-9

Bailey MJ, Biely P, and Poutanen K. 1992. Interlaboratory testing of methods for assay of xylanase activity. Journal of Biotechnology 23:257-270. https://doi.org/10.1016/0168-

Bakalidou A, Kämpfer P, Berchtold M, Kuhnigk T, Wenzel M, and König H. 2002. Cellulosimicrobium variabile sp. nov., a cellulolytic bacterium from the hindgut of the termite Mastotermes darwiniensis. International Journal of Systematic and Evolutionary Microbiology 52:1185-1192. 10.1099/00207713-52-4-1185

Bankevich A, Nurk S, Antipov D, Gurevich AA, Dvorkin M, Kulikov AS, Lesin VM, Nikolenko SI, Pham S, Prjibelski AD, Pyshkin AV, Sirotkin AV, Vyahhi N, Tesler G, Alekseyev MA, and Pevzner PA. 2012. SPAdes: a new genome assembly algorithm and its applications to 
557

558

559

560

561

562

563

564

565

566

567

568

569

570

571

572

573

574

575

576

577

578

579

580

581

582

583

584

585

586

587

588

589

590

591

592

593

594

595

596

single-cell sequencing. Journal of computational biology : a journal of computational molecular cell biology 19:455-477. 10.1089/cmb.2012.0021

Belghith KS, Dahech I, Belghith H, and Mejdoub H. 2012. Microbial production of levansucrase for synthesis of fructooligosaccharides and levan. International Journal of Biological Macromolecules 50:451-458. 10.1016/j.ijbiomac.2011.12.033

Biz A, Farias FC, Motter FA, de Paula DH, Richard P, Krieger N, and Mitchell DA. 2014. Pectinase activity determination: an early deceleration in the release of reducing sugars throws a spanner in the works! PLOS ONE 9:e109529-e109529. 10.1371/journal.pone.0109529

Bolger AM, Lohse M, and Usadel B. 2014. Trimmomatic: a flexible trimmer for Illumina sequence data. Bioinformatics 30:2114-2120. 10.1093/bioinformatics/btu170

Brown JM, Steigerwalt AG, Morey RE, Daneshvar MI, Romero L-J, and McNeil MM. 2006. Characterization of clinical isolates previously identified as Oerskovia turbata: proposal of Cellulosimicrobium funkei sp. nov. and emended description of the genus Cellulosimicrobium. International Journal of Systematic and Evolutionary Microbiology 56:801-804. https://doi.org/10.1099/ijs.0.63882-0

Calusinska M, Marynowska M, Bertucci M, Untereiner B, Klimek D, Goux X, Sillam-Dussès D, Gawron P, Halder R, Wilmes P, Ferrer P, Gerin P, Roisin Y, and Delfosse P. 2020. Integrative omics analysis of the termite gut system adaptation to Miscanthus diet identifies lignocellulose degradation enzymes. Communications Biology 3:275. 10.1038/s42003020-1004-3

Chen SJ, Lam MQ, Thevarajoo S, Abd Manan F, Yahya A, and Chong CS. 2020. Genome analysis of cellulose and hemicellulose degrading Micromonospora sp. CP22. 3 Biotech 10:160. $10.1007 / \mathrm{s} 13205-020-2148-\mathrm{z}$

Chutani P, and Sharma KK. 2016. Concomitant production of xylanases and cellulases from Trichoderma longibrachiatum MDU-6 selected for the deinking of paper waste. Bioprocess and Biosystems Engineering 39:747-758. 10.1007/s00449-016-1555-3

Dahech I, Belghith KS, Hamden K, Feki A, Belghith H, and Mejdoub H. 2011. Antidiabetic activity of levan polysaccharide in alloxan-induced diabetic rats. International Journal of Biological Macromolecules 49:742-746. https://doi.org/10.1016/j.ijbiomac.2011.07.007

Dashtban M, Schraft H, and Qin W. 2009. Fungal bioconversion of lignocellulosic residues; opportunities \& perspectives. International Journal of Biological Sciences 5:578-595. 10.7150/ijbs.5.578

Débarbouillé M, Martin-Verstraete I, Arnaud M, Klier A, and Rapoport G. 1991. Positive and negative regulation controlling expression of the sac genes in Bacillus subtilis. Research in Microbiology 142:757-764. 10.1016/0923-2508(91)90052-c

Diken E, Ozer T, Arikan M, Emrence Z, Oner ET, Ustek D, and Arga KY. 2015. Genomic analysis reveals the biotechnological and industrial potential of levan producing halophilic extremophile, Halomonas smyrnensis AAD6T. Springerplus 4:393. 10.1186/s40064-015$1184-3$ 
597 Dogsa I, Brloznik M, Stopar D, and Mandic-Mulec I. 2013. Exopolymer diversity and the role of

598

599

600

601

602

603

604

605

606

607

608

609

610

611

612

613

614

615

616

617

618

619

620

621

622

623

624

625

626

627

628

629

630

631

632

633

634

635 levan in Bacillus subtilis biofilms. PLOS ONE 8:e62044. 10.1371/journal.pone.0062044

Eida AA, Bougouffa S, Alam I, Saad MM, and Hirt H. 2020. Complete genome sequence of the endophytic bacterium Cellulosimicrobium sp. JZ28 isolated from the root endosphere of the perennial desert tussock grass Panicum turgidum. Archives of Microbiology 202:15631569. 10.1007/s00203-020-01859-2

Feng J, Gu Y, Quan Y, Zhang W, Cao M, Gao W, Song C, Yang C, and Wang S. 2015. Recruiting a new strategy to improve levan production in Bacillus amyloliquefaciens. Scientific Reports 5:13814. 10.1038/srep13814

Galperin MY, Makarova KS, Wolf YI, and Koonin EV. 2015. Expanded microbial genome coverage and improved protein family annotation in the COG database. Nucleic Acids Research 43:D261-269. 10.1093/nar/gku1223

Ghose TK. 1987. Measurement of cellulase activities. Pure and Applied Chemistry 59:257-268. doi:10.1351/pac198759020257

Gilbert HJ, Knox JP, and Boraston AB. 2013. Advances in understanding the molecular basis of plant cell wall polysaccharide recognition by carbohydrate-binding modules. Current Opinion in Structural Biology 23:669-677. 10.1016/j.sbi.2013.05.005

Gojgic-Cvijovic GD, Jakovljevic DM, Loncarevic BD, Todorovic NM, Pergal MV, Ciric J, Loos K, Beskoski VP, and Vrvic MM. 2019. Production of levan by Bacillus licheniformis NS032 in sugar beet molasses-based medium. International Journal of Biological Macromolecules 121:142-151. https://doi.org/10.1016/j.ijbiomac.2018.10.019

Gray DA, White JBR, Oluwole AO, Rath P, Glenwright AJ, Mazur A, Zahn M, Baslé A, Morland C, Evans SL, Cartmell A, Robinson CV, Hiller S, Ranson NA, Bolam DN, and van den Berg B. 2021. Insights into SusCD-mediated glycan import by a prominent gut symbiont. Nature Communications 12:44. 10.1038/s41467-020-20285-y

Grissa I, Vergnaud G, and Pourcel C. 2007. CRISPRFinder: a web tool to identify clustered regularly interspaced short palindromic repeats. Nucleic Acids Research 35:W52-W57. 10.1093/nar/gkm360

Gupta P, Samant K, and Sahu A. 2012. Isolation of cellulose-degrading bacteria and determination of their cellulolytic potential. International Journal of Microbiology 2012:578925. $10.1155 / 2012 / 578925$

Hamada M, Shibata C, Tamura T, Nurkanto A, Ratnakomala S, Lisdiyanti P, and Suzuki K-i. 2016. Cellulosimicrobium marinum sp. nov., an actinobacterium isolated from sea sediment. Archives of Microbiology 198:439-444. 10.1007/s00203-016-1204-x

Hugouvieux-Cotte-Pattat N, Condemine G, and Shevchik VE. 2014. Bacterial pectate lyases, structural and functional diversity. Environmental Microbiology Reports 6:427-440. $10.1111 / 1758-2229.12166$

Jäger G, and Büchs J. 2012. Biocatalytic conversion of lignocellulose to platform chemicals. Biotechnology Journal 7:1122-1136. 10.1002/biot.201200033 
636 Jakob F, Quintero Y, Musacchio A, Estrada-de los Santos P, Hernández L, and Vogel RF. 2019.

637

638

639

640

641

642

643

644

645

646

647

648

649

650

651

652

653

654

655

656

657

658

659

660

661

662

663

664

665

666

667

668

669

670

671

672

673

674

675

Acetic acid bacteria encode two levansucrase types of different ecological relationship. Environmental Microbiology 21:4151-4165. https://doi.org/10.1111/1462-2920.14768

Jayani RS, Saxena S, and Gupta R. 2005. Microbial pectinolytic enzymes: A review. Process Biochemistry 40:2931-2944. https://doi.org/10.1016/j.procbio.2005.03.026

Jones P, Binns D, Chang HY, Fraser M, Li W, McAnulla C, McWilliam H, Maslen J, Mitchell A, Nuka G, Pesseat S, Quinn AF, Sangrador-Vegas A, Scheremetjew M, Yong SY, Lopez R, and Hunter S. 2014. InterProScan 5: genome-scale protein function classification. Bioinformatics 30:1236-1240. 10.1093/bioinformatics/btu031

Kamlage B. 1996. Methods for general and molecular bacteriology. . Food / Nahrung 40:103-103. https://doi.org/10.1002/food.19960400226

Kamsani N, Salleh MM, Yahya A, and Chong CS. 2016. Production of lignocellulolytic enzymes by microorganisms isolated from Bulbitermes sp. termite gut in solid-state fermentation. Waste and Biomass Valorization 7:357-371. 10.1007/s12649-015-9453-5

Lee I, Ouk Kim Y, Park SC, and Chun J. 2016. OrthoANI: An improved algorithm and software for calculating average nucleotide identity. International Journal of Systematic and Evolutionary Microbiology 66:1100-1103. 10.1099/ijsem.0.000760

Lee SH, and Lee YE. 2014. Cloning and characterization of a multidomain GH10 xylanase from Paenibacillus sp. DG-22. Journal of Microbiology and Biotechnology 24:1525-1535. 10.4014/jmb.1407.07077

Li Y, Lei L, Zheng L, Xiao X, Tang H, and Luo C. 2020. Genome sequencing of gut symbiotic Bacillus velezensis $\mathrm{LC} 1$ for bioethanol production from bamboo shoots. Biotechnology for Biofuels 13:34. 10.1186/s13068-020-1671-9

Mardo K, Visnapuu T, Vija H, Aasamets A, Viigand K, and Alamäe T. 2017. A highly active endo-levanase BT1760 of a dominant mammalian gut commensal bacteroides thetaiotaomicron cleaves not only various bacterial levans, but also levan of Timothy grass. PLOS ONE 12:e0169989. 10.1371/journal.pone.0169989

Martínez-Fleites C, Ortíz-Lombardía M, Pons T, Tarbouriech N, Taylor EJ, Arrieta JG, Hernández L, and Davies GJ. 2005. Crystal structure of levansucrase from the Gram-negative bacterium Gluconacetobacter diazotrophicus. The Biochemical Journal 390:19-27. 10.1042/BJ20050324

McLean BW, Boraston AB, Brouwer D, Sanaie N, Fyfe CA, Warren RA, Kilburn DG, and Haynes CA. 2002. Carbohydrate-binding modules recognize fine substructures of cellulose. The Journal of biological chemistry 277:50245-50254. 10.1074/jbc.M204433200

Meier-Kolthoff JP, Auch AF, Klenk HP, and Göker M. 2013. Genome sequence-based species delimitation with confidence intervals and improved distance functions. $B M C$ Bioinformatics 14:60. 10.1186/1471-2105-14-60

Mercimek Takcı HA, and Turkmen FU. 2016. Extracellular pectinase production and purification from a newly isolated Bacillus subtilis strain. International Journal of Food Properties 19:2443-2450. 10.1080/10942912.2015.1123270

PeerJ reviewing PDF | (2021:03:58621:1:1:NEW 25 May 2021) 
676 Miller GL. 1959. Use of dinitrosalicylic acid reagent for determination of reducing sugar.

677

678

679

680

681

682

683

684

685

686

687

688

689

690

691

692

693

694

695

696

697

698

699

700

701

702

703

704

705

706

707

708

709

710

711

712

713

714

715 Analytical Chemistry 31:426-428. 10.1021/ac60147a030

Oh M, Kim JH, Yoon JH, Schumann P, and Kim W. 2018. Cellulosimicrobium arenosum sp. nov., Isolated from Marine Sediment Sand. Current Microbiology 75:901-906. 10.1007/s00284018-1464-6

Ohkuma M. 2003. Termite symbiotic systems: efficient bio-recycling of lignocellulose. Applied microbiology and biotechnology 61:1-9. 10.1007/s00253-002-1189-z

Pandey AK, Edgard G, and Negi S. 2016. Optimization of concomitant production of cellulase and xylanase from Rhizopus oryzae SN5 through EVOP-factorial design technique and application in Sorghum Stover based bioethanol production. Renewable Energy 98:51-56. https://doi.org/10.1016/j.renene.2016.05.071

Pasari N, Gupta M, Eqbal D, and Yazdani SS. 2019. Genome analysis of Paenibacillus polymyxa A18 gives insights into the features associated with its adaptation to the termite gut environment. Scientific Reports 9:6091. 10.1038/s41598-019-42572-5

Pereira Y, Petit-Glatron MF, and Chambert R. 2001. yveB, Encoding endolevanase LevB, is part of the sacB-yveB-yveA levansucrase tricistronic operon in Bacillus subtilis. Microbiology 147:3413-3419. 10.1099/00221287-147-12-3413

Phi QT, Park YM, Seul KJ, Ryu CM, Park SH, Kim JG, and Ghim SY. 2010. Assessment of rootassociated Paenibacillus polymyxa groups on growth promotion and induced systemic resistance in pepper. Journal of Microbiology and Biotechnology 20:1605-1613.

Powers EM. 1995. Efficacy of the Ryu nonstaining KOH technique for rapidly determining gram reactions of food-borne and waterborne bacteria and yeasts. Applied and Environmental Microbiology 61:3756-3758. 10.1128/AEM.61.10.3756-3758.1995

Qin W, Fan F, Zhu Y, Huang X, Ding A, Liu X, and Dou J. 2018. Anaerobic biodegradation of benzo(a)pyrene by a novel Cellulosimicrobium cellulans CWS2 isolated from polycyclic aromatic hydrocarbon-contaminated soil. Brazilian Journal of Microbiology 49:258-268. https://doi.org/10.1016/j.bjm.2017.04.014

Raga-Carbajal E, López-Munguía A, Alvarez L, and Olvera C. 2018. Understanding the transfer reaction network behind the non-processive synthesis of low molecular weight levan catalyzed by Bacillus subtilis levansucrase. Scientific Reports 8:15035. 10.1038/s41598018-32872-7

Schumann P, Weiss N, and Stackebrandt E. 2001. Reclassification of Cellulomonas cellulans (Stackebrandt and Keddie 1986) as Cellulosimicrobium cellulans gen. nov., comb. nov. International Journal of Systematic and Evolutionary Microbiology 51:1007-1010. https://doi.org/10.1099/00207713-51-3-1007

Senthilkumar V, Rameshkumar N, Busby SJ, and Gunasekaran P. 2004. Disruption of the Zymomonas mobilis extracellular sucrase gene ( $\mathrm{sacC}$ ) improves levan production. Journal of Applied Microbiology 96:671-676. 10.1111/j.1365-2672.2003.02169.x

Sharma A, Gilbert JA, and Lal R. 2016. (Meta)genomic insights into the pathogenome of Cellulosimicrobium cellulans. Scientific Reports 6:25527. 10.1038/srep25527 
716 Shih IL, Yu YT, Shieh CJ, and Hsieh CY. 2005. Selective production and characterization of levan

717

718

719

720

721

722

723

724

725

726

727

728

729

730

731

732

733

734

735

736

737

738

739

740

741

742

743

744

745

746

747

748

749

750

751

752

753

754 by Bacillus subtilis (Natto) Takahashi. Journal of Agricultural and Food Chemistry 53:8211-8215. 10.1021/jf058084o

Somogyi M. 1945. A new reagent for the determination of sugars. Journal of Biological Chemistry 160:61-68. https://doi.org/10.1016/S0021-9258(18)43097-9

Sultanpuram VR, Mothe T, Chintalapati S, and Chintalapati VR. 2015. Cellulosimicrobium aquatile sp. nov., isolated from Panagal reservoir, Nalgonda, India. Antonie Van Leeuwenhoek 108:1357-1364. 10.1007/s10482-015-0588-y

Tamura K, Stecher G, Peterson D, Filipski A, and Kumar S. 2013. MEGA6: Molecular evolutionary genetics analysis version 6.0. Molecular Biology and Evolution 30:27252729. 10.1093/molbev/mst197

Teather RM, and Wood PJ. 1982. Use of Congo red-polysaccharide interactions in enumeration and characterization of cellulolytic bacteria from the bovine rumen. Applied and Environmental Microbiology 43:777-780. 10.1128/AEM.43.4.777-780.1982

Tokuda G, and Watanabe H. 2007. Hidden cellulases in termites: revision of an old hypothesis. Biology Letters 3:336-339. 10.1098/rsbl.2007.0073

Ventorino V, Ionata E, Birolo L, Montella S, Marcolongo L, de Chiaro A, Espresso F, Faraco V, and Pepe O. 2016. Lignocellulose-adapted endo-cellulase producing Streptomyces strains for bioconversion of cellulose-based materials. Frontiers in Microbiology 7. $10.3389 /$ fmicb.2016.02061

Verspreet J, Dornez E, Van den Ende W, Delcour JA, and Courtin CM. 2015. Cereal grain fructans: Structure, variability and potential health effects. Trends in Food Science \& Technology 43:32-42. https://doi.org/10.1016/j.tifs.2015.01.006

Walia A, Guleria S, Mehta P, Chauhan A, and Parkash J. 2017. Microbial xylanases and their industrial application in pulp and paper biobleaching: a review. 3 Biotech 7:11. 10.1007/s13205-016-0584-6

Wang Y, Coleman-Derr D, Chen G, and Gu YQ. 2015. OrthoVenn: a web server for genome wide comparison and annotation of orthologous clusters across multiple species. Nucleic Acids Research 43:W78-84. 10.1093/nar/gkv487

Wattam AR, Davis JJ, Assaf R, Boisvert S, Brettin T, Bun C, Conrad N, Dietrich EM, Disz T, Gabbard JL, Gerdes S, Henry CS, Kenyon RW, Machi D, Mao C, Nordberg EK, Olsen GJ, Murphy-Olson DE, Olson R, Overbeek R, Parrello B, Pusch GD, Shukla M, Vonstein V, Warren A, Xia F, Yoo H, and Stevens RL. 2017. Improvements to PATRIC, the allbacterial bioinformatics database and analysis resource center. Nucleic Acids Research 45:D535-d542. 10.1093/nar/gkw1017

Wi SG, Cho EJ, Lee D-S, Lee SJ, Lee YJ, and Bae H-J. 2015. Lignocellulose conversion for biofuel: a new pretreatment greatly improves downstream biocatalytic hydrolysis of various lignocellulosic materials. Biotechnology for Biofuels 8:228. 10.1186/s13068-0150419-4

Peer) reviewing PDF | (2021:03:58621:1:1:NEW 25 May 2021) 
755 Wong LJ, H'Ng P S, Wong SY, Lee SH, Lum WC, Chai EW, Wong WZ, and Chin KL. 2014.

756

757

758

759

760

761

762

763

764

765

766

767

768

769

770

771

772

773

774

775

776

777

778

779

780

781

782

783

784

785

786

787

788

789

790

791

792

793

794
Termite digestomes as a potential source of symbiotic microbiota for lignocelluloses degradation: a review. Pakistan Journal of Biological Sciences 17:956-963. 10.3923/pjbs.2014.956.963

Yoo SH, Yoon EJ, Cha J, and Lee HG. 2004. Antitumor activity of levan polysaccharides from selected microorganisms. International Journal of Biological Macromolecules 34:37-41. 10.1016/j.ijbiomac.2004.01.002

Yoon JH, Kang SJ, Schumann P, and Oh TK. 2007. Cellulosimicrobium terreum sp. nov., isolated from soil. International Journal of Systematic and Evolutionary Microbiology 57:24932497. 10.1099/ijs.0.64889-0

Zhao Y, Yuan Y, Zhang X, Li Y, Li Q, Zhou Y, and Gao J. 2018. Screening of a novel polysaccharide lyase family 10 pectate lyase from Paenibacillus polymyxa KF-1: Cloning, expression and characterization. Molecules (Basel, Switzerland) 23:2774. 10.3390/molecules 23112774

Zheng F, Zhang W, Chu X, Dai Y, Li J, Zhao H, Wen L, Yue H, and Yu S. 2017. Genome sequencing of strain Cellulosimicrobium sp. TH-20 with ginseng biotransformation ability. 3 Biotech 7:237. 10.1007/s13205-017-0850-2

\section{Table 1: Genomic features of $C$. cellulans MP1.}

Table 2: List of predicted cellulolytic and hemicellulolytic enzymes present in the genome of C. cellulans MP1.

\section{Figure legends}

Figure 1: Identification of the strain MP1. The Maximum-likelihood phylogenetic tree based the 16S rRNA sequence of strain MP1 and representatives of reference type strains. Bar: 0.05 substitutions per site.

Figure 2: Phylogenomic classification of Cellulosimicrobium sp. MP1 based on genome analysis. (A) Heatmap of OrthoANI values for Cellulosimicrobium sp. MP1 and five closely related species. (B) Genome Basic Local Alignment Search Tool (BLAST) distance phylogenies (GBDP) using Type Strain Genome Server (TYGS) platform. Branch lengths are scaled in terms of GBDP distance formula $d 5$. Numbers above branches are GBDP pseudo-bootstrap support values $>60 \%$ from 100 replications, with an average branch support of $84.3 \%$. Tree was rooted at midpoint.

Peer] reviewing PDF | (2021:03:58621:1:1:NEW 25 May 2021) 
Figure 3: Circular genome map of $C$. cellulans MP1.

798

Figure 4: The functional annotations of $C$. cellulans MP1. (A) Cluster of orthologous gene

799

800 (COG) classification.

(B) Gene ontology (GO) functional classification.

801

802

803

804

805

806

807

808

809

810

811

812

813

814

815

816

817

818

819

820

821

822

823

824

825

826

827

828

829

830

831

832

833

834
Figure 5: Comparative genomes between $C$. cellulans MP1 and three other $C$. cellulans strains. (A) Venn diagram represents the numbers of unique and shared orthologous genes of each strain. (B) Comparative genomic analysis of CAZymes across C. cellulans strains.

Figure 6: Enzymatic activities of $C$. cellulans MP1 observed in different incubation periods. Mean values with different letters a-d are significantly different according to the Fisher LCD test $(P<0.05)$.

Figure 7: Levan biosynthesis in $C$. cellulans MP1. (A) Genetic organization of levan operon in C. cellulans MP1, Zymomonas mobilis B-14023 and Bacillus subtilis QB112. The $l s$ and sacClev $B$ homologous genes are denoted in black and gray, respectively. (B) Time course of levan production. (C) Proposed mechanism for levan and levan-type fructooligosaccharide (L-FOs) biosynthesis.

\section{Supplemental Information}

Table S1: CMCase and FPase activities of strain MP1 with cultivation times.

Table S2: Physiological and biochemical characteristics of strain MP1.

Table S3: Predicted genes associated cellulose and hemicellulose degradation.

Figure S1: Multiple genomes alignments were generated by mapping genome sequences of three closely related $C$. cellulans strains against MP1.

Figure S2: Protein sequence alignments of levansucrase homologs across known bacteria. Alignment of Ls homologs was performed with Clustal W. Enzyme source and Protein IDs correspond to: Gdia, Gluconacetobacter diazotrophicus (WP_012222901); Bvie, Burkholderia vietnamiensis (WP_011882121); Mce, Cellulosimicrobium cellulans MP1; Msac, Microbacterium saccharophilum (WP_147051238); Achr, Azotobacter chroococcum (WP_052264013). The red and blue color letters indicate percentage of amino acid identity. The conserved Cys is enclosed in the black box and marked with an asterisk (*).

Peer) reviewing PDF | (2021:03:58621:1:1:NEW 25 May 2021) 


\section{Figure 1}

Identification of the strain MP1.

The Maximum-likelihood phylogenetic tree based the 16S rRNA sequence of strain MP1 and representatives of reference type strains. Bar: 0.05 substitutions per site

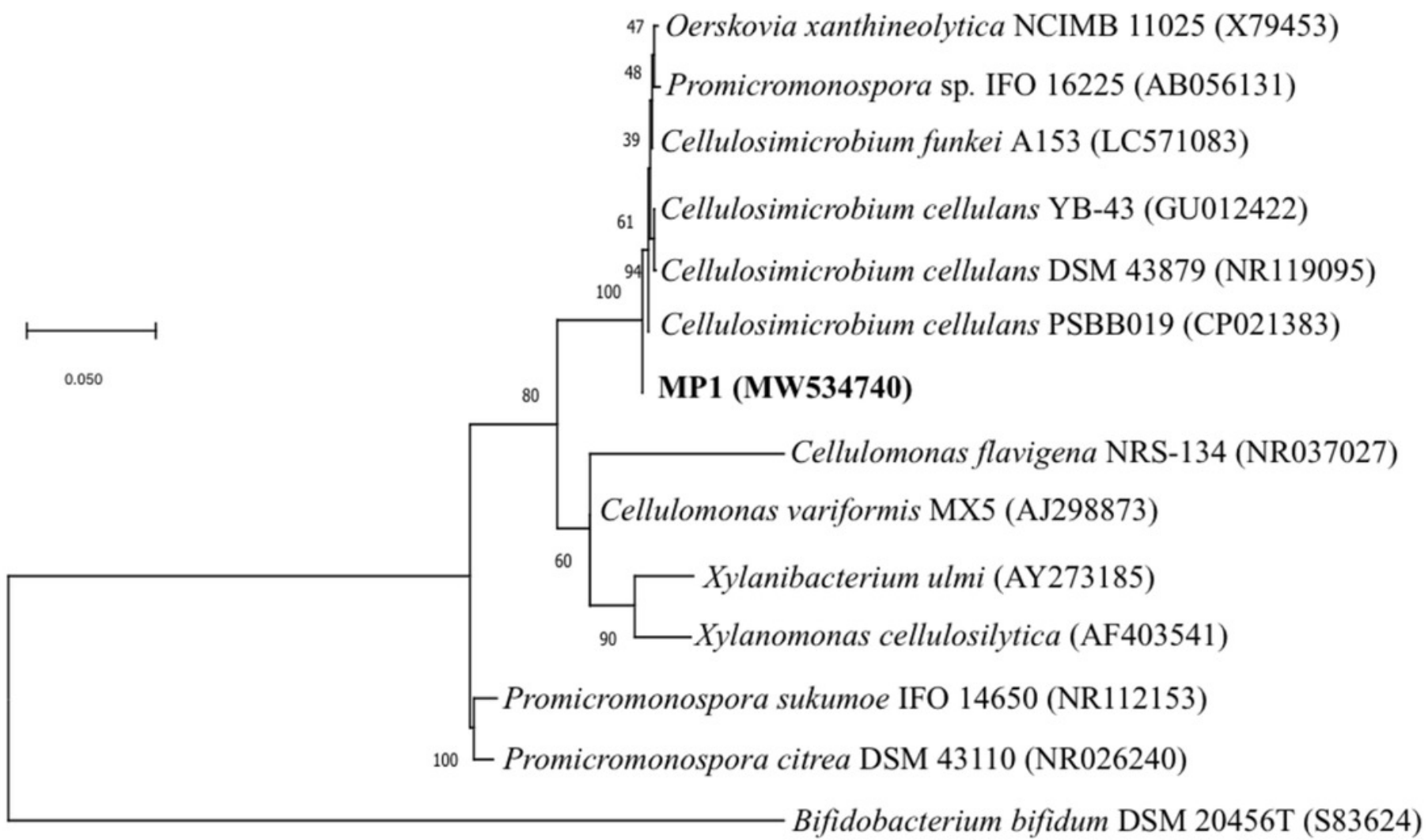


Figure 2

Phylogenomic classification of Cellulosimicrobium sp. MP1 based on genome analysis.

(A) Heatmap of OrthoANI values for Cellulosimicrobium sp. MP1 and five closely related species. (B) Genome Basic Local Alignment Search Tool (BLAST) distance phylogenies (GBDP) using Type Strain Genome Server (TYGS) platform. Branch lengths are scaled in terms of GBDP distance formula d5. Numbers above branches are GBDP pseudo-bootstrap support values $>60 \%$ from 100 replications, with an average branch support of $84.3 \%$. Tree was rooted at midpoint.
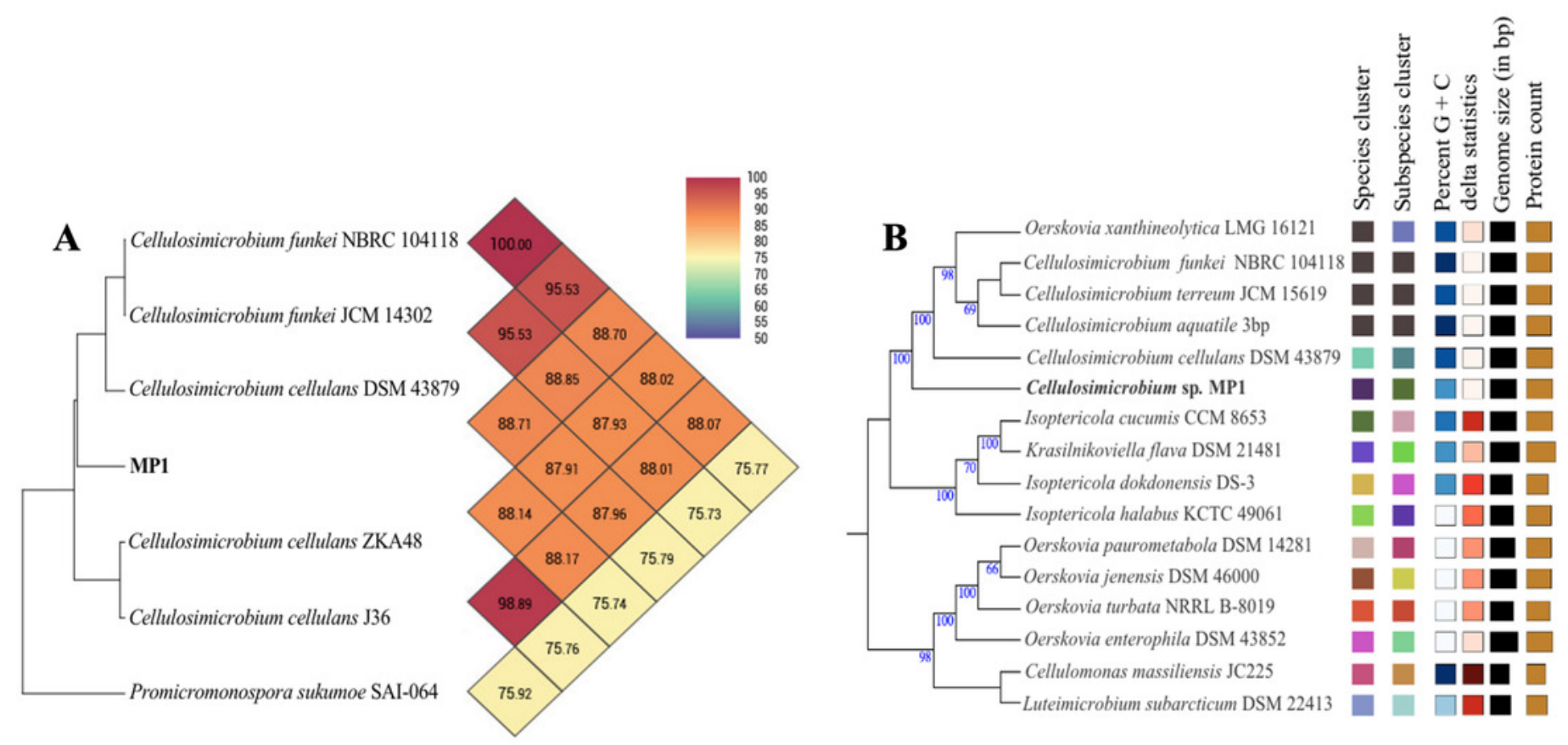
Figure 3

Circular genome map of $C$. cellulans MP1

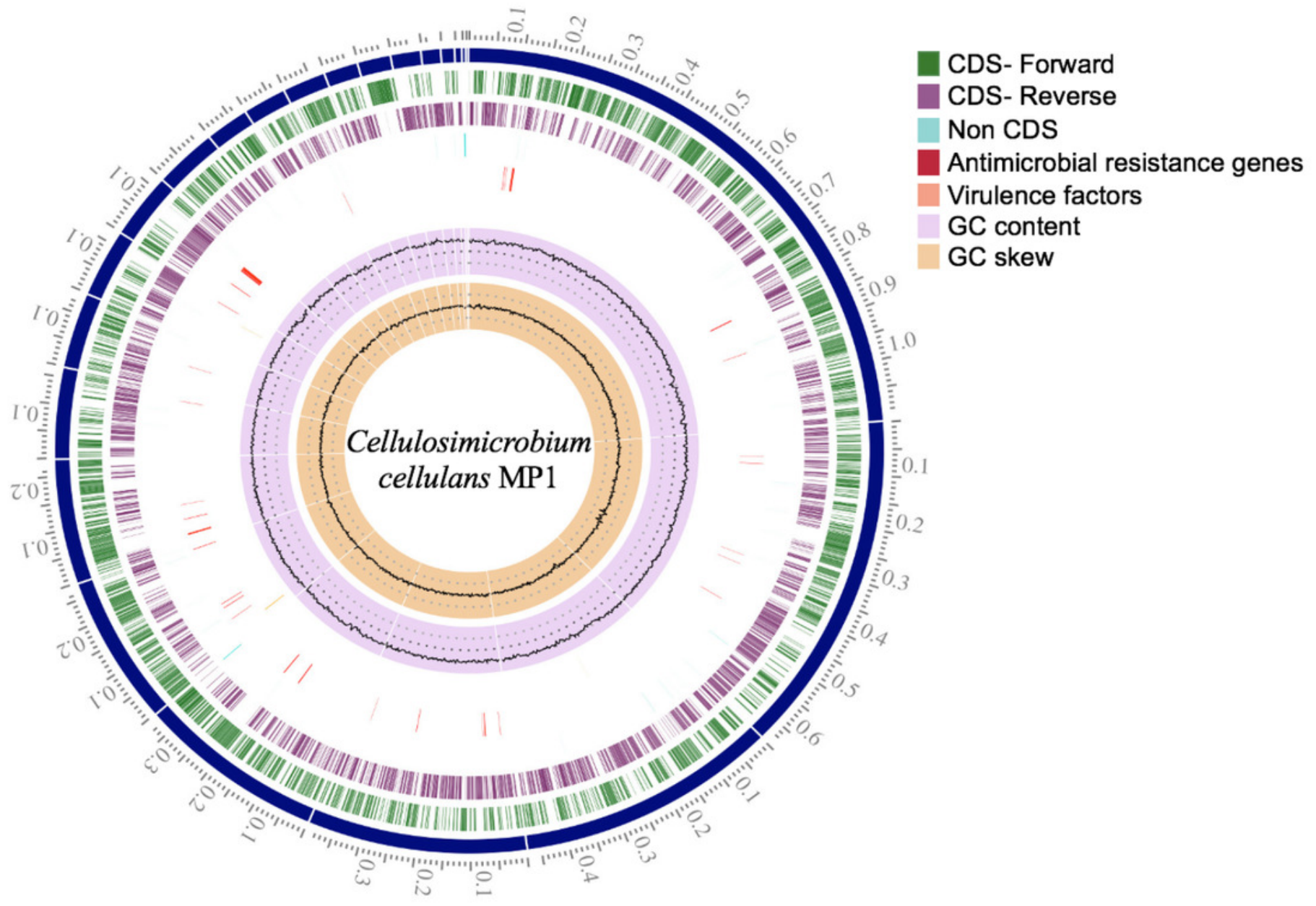


Figure 4

The functional annotations of $C$. cellulans MP1

(A) Cluster of orthologous gene (COG) classification. (B) Gene ontology (GO) functional classification 


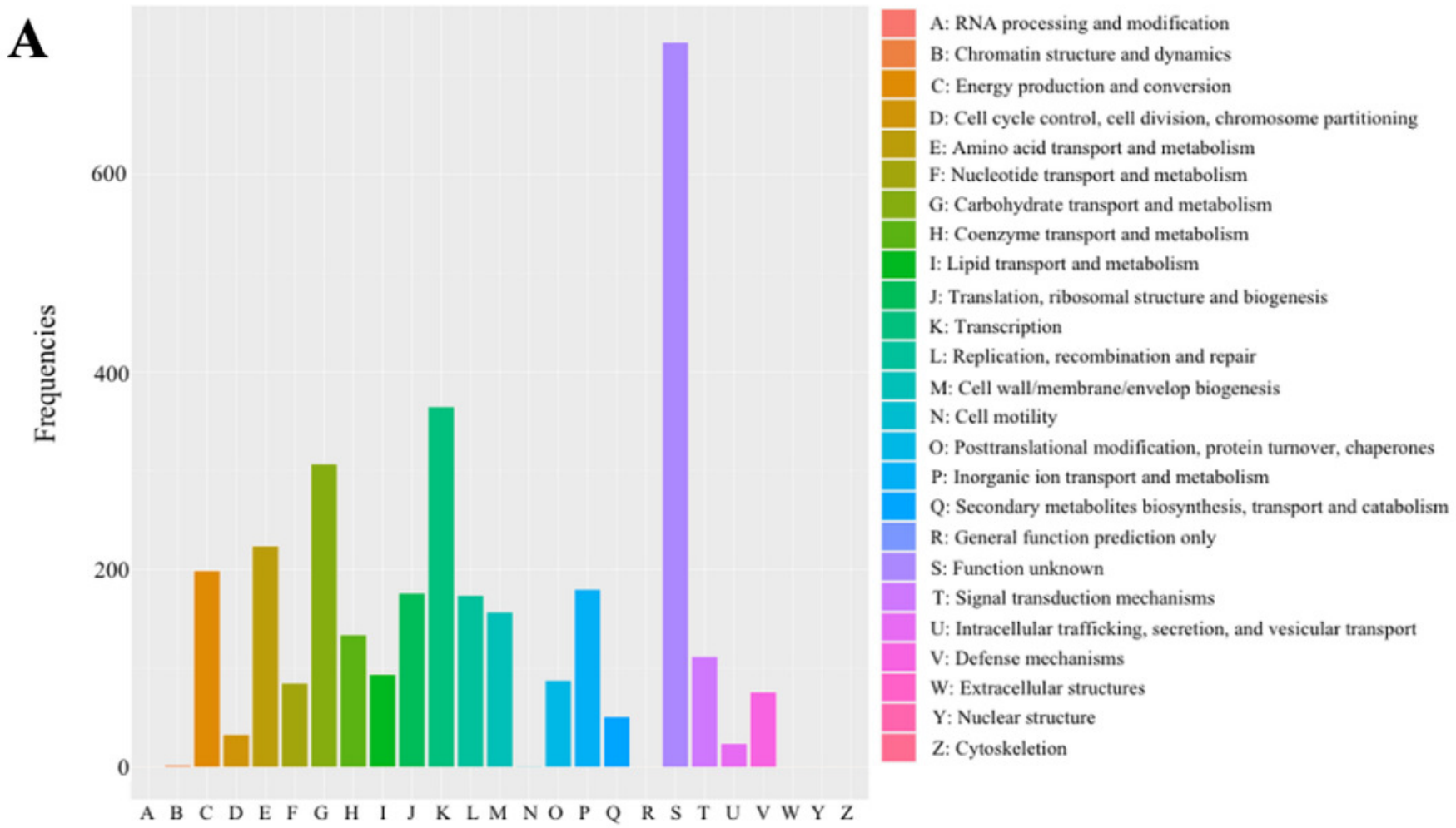

B

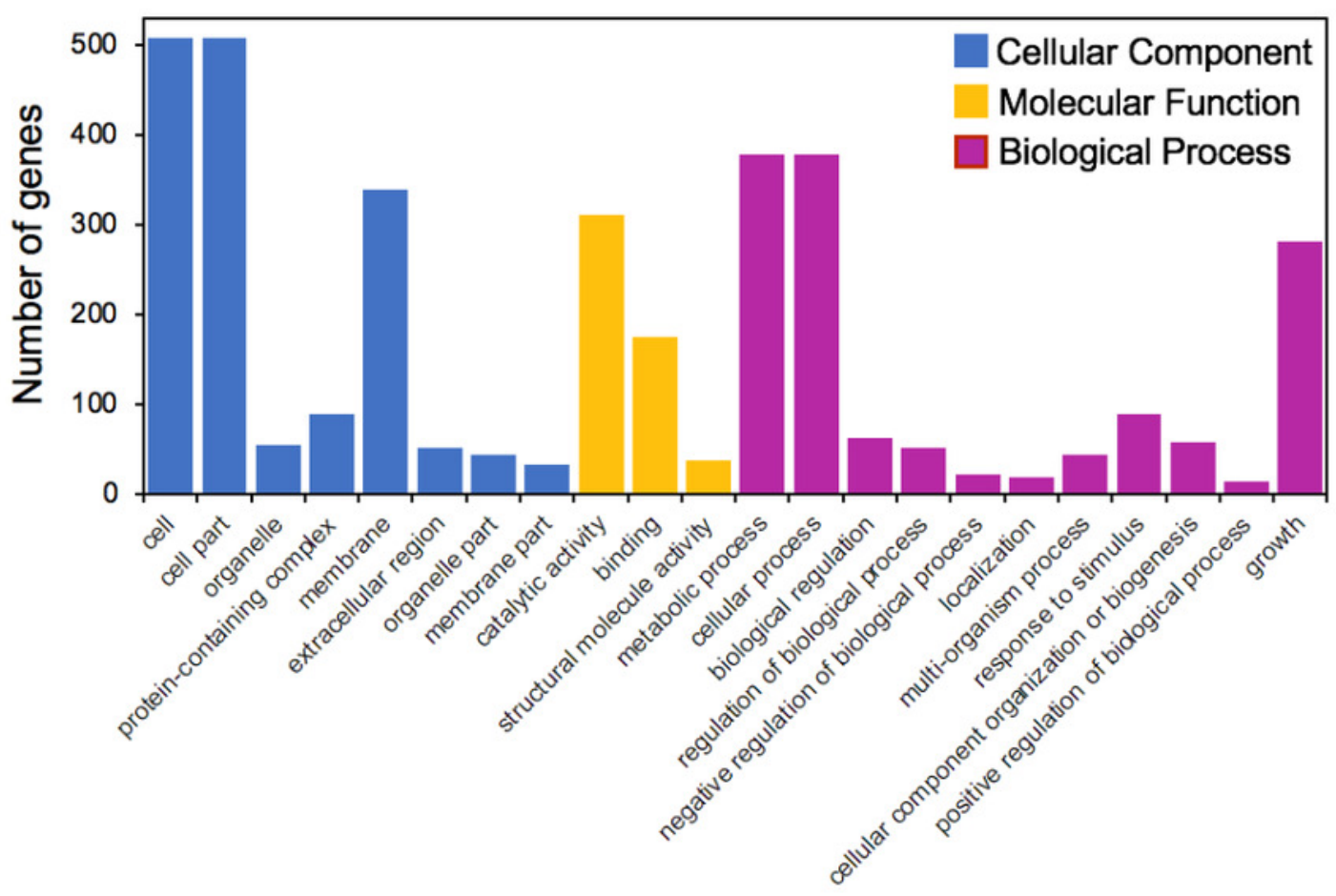


Figure 5

Comparative genomes between $C$. cellulans MP1 and three other $C$. cellulans strains

(A) Venn diagram represents the numbers of unique and shared orthologous genes of each strain. (B) Comparative genomic analysis of CAZymes across C. cellulans strains.
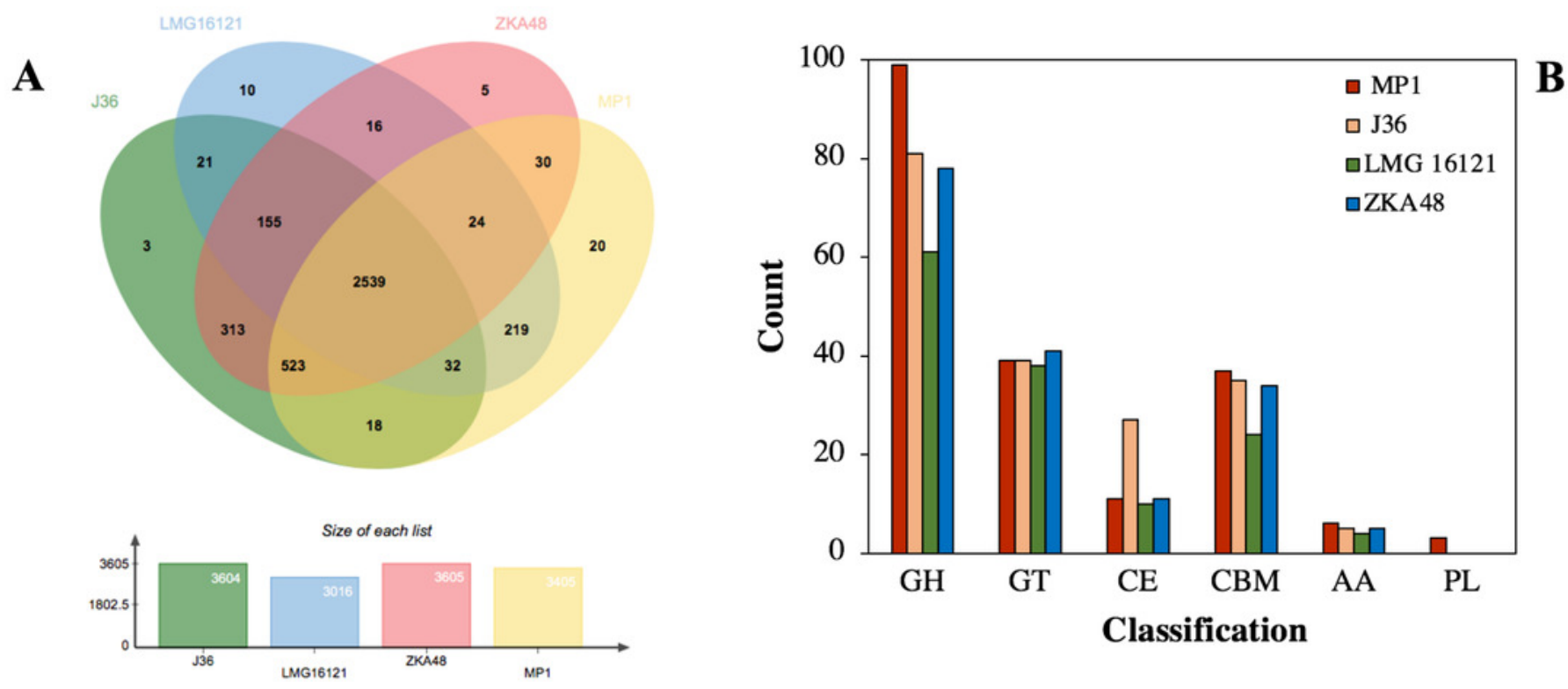
Figure 6

Enzymatic activities of $C$. cellulans MP1 observed in different incubation periods.

Mean values with different letters a-d are significantly different according to the Fisher LCD test $(P<0.05)$.

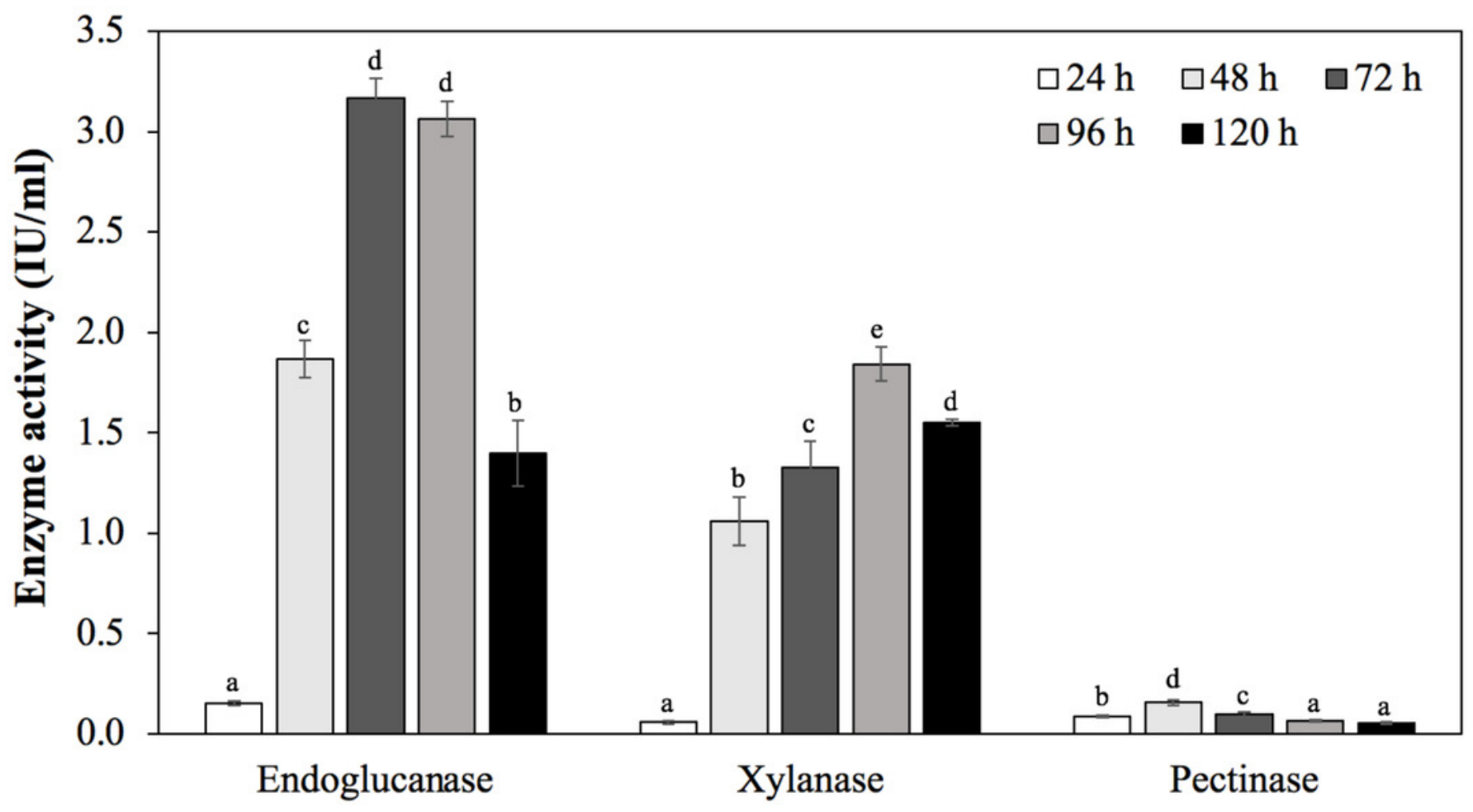


Figure 7

Levan biosynthesis in C. cellulans MP1.

(A) Genetic organization of levan operon in C. cellulans MP1, Zymomonas mobilis B-14023 and Bacillus subtilis QB112. The Is and sacC-levB homologous genes are denoted in black and gray, respectively. (B) Time course of levan production. (C) Proposed mechanism for levan and levan-type fructooligosaccharide (L-FOs) biosynthesis.

A Cellulosimicrobium cellulans MP1

Zymomonas mobilis B-14023

Bacillus subtilis QB112
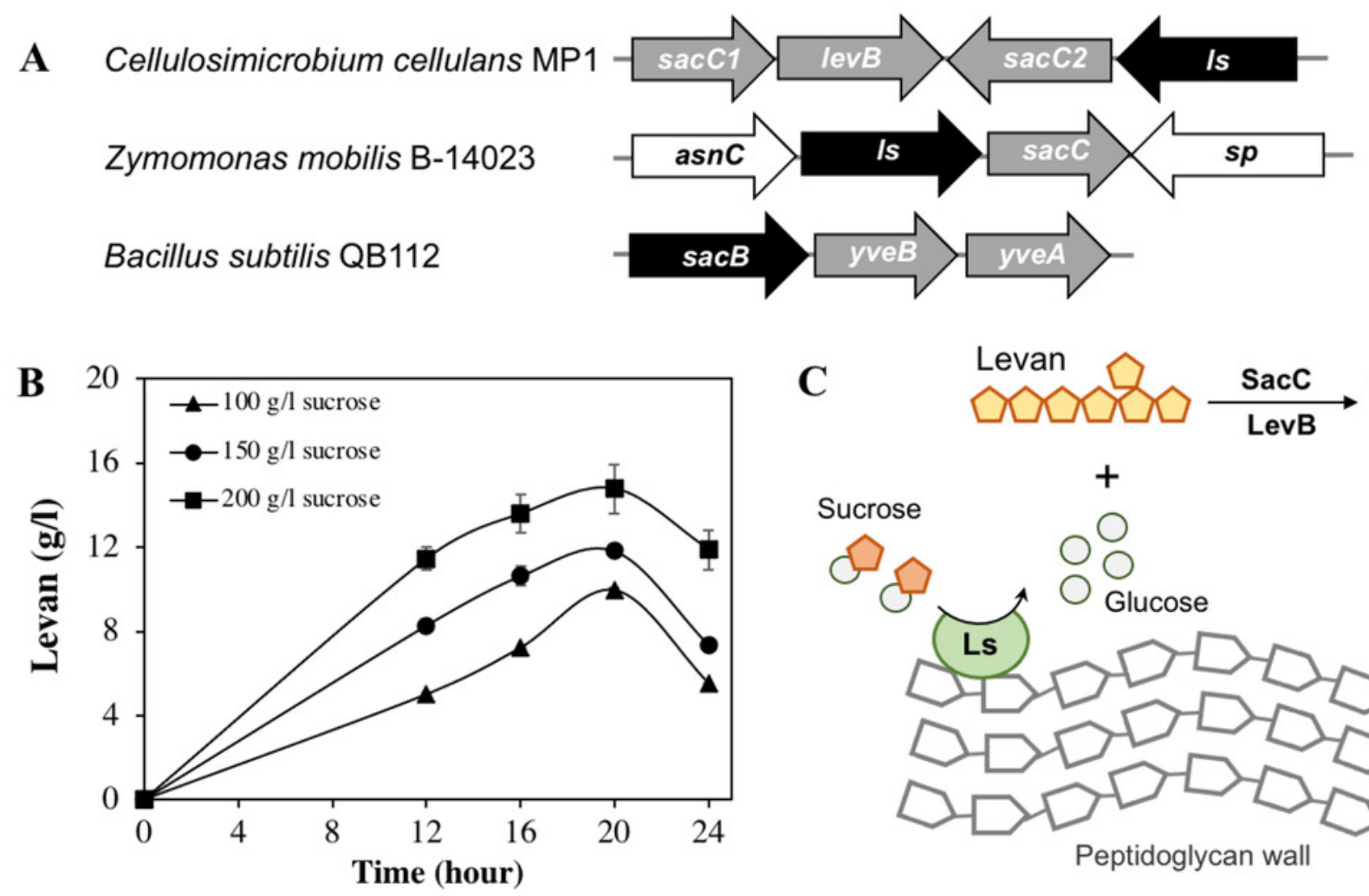

C
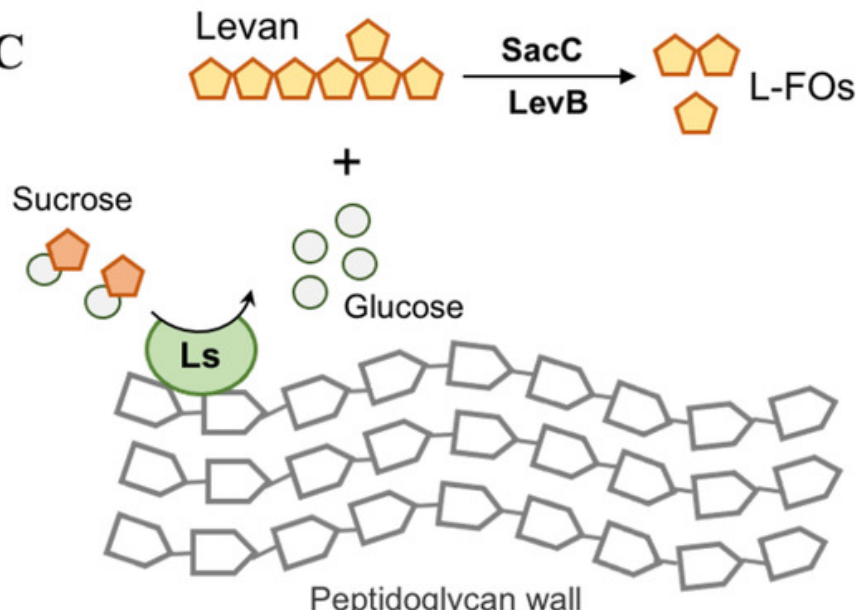
Table $\mathbf{1}$ (on next page)

Genomic features of $C$. cellulans MP1 
1

2

3

4

5

6

7

8

9

10

11
Table 1: Genomic features of $C$. cellulans MP1

\section{Chromosome}

$4,580,223$

23

0

73.9

4,088

3,964

61

55

ncRNAs 3

Pseudogenes 63

CRISPRS

0

JAFGYF000000000
Genome size (bp)

No. of plasmids

$\mathrm{G}+\mathrm{C}$ content $(\%)$

CDSs (coding)

rRNAs 
Table 2 (on next page)

List of predicted cellulolytic and hemicellulolytic enzymes present in the genome of $C$. cellulans MP1 
Table 2: List of predicted cellulolytic and hemicellulolytic enzymes present in the genome of $C$. cellulans MP1

\begin{tabular}{|c|c|c|}
\hline Classification & Locus tag & Predicted function \\
\hline \multirow[t]{14}{*}{$\begin{array}{l}\text { Cellulose- } \\
\text { related }\end{array}$} & $\begin{array}{l}\text { Orf_454, Orf_1616, Orf_2130, } \\
\text { Orf_2755, Orf_3244 }\end{array}$ & Endoglucanase [EC 3.2.1.4] \\
\hline & Orf_1607, Orf_1610, Orf_1611 & Exoglucanase [EC 3.2.1.91] \\
\hline & Orf_2289 & Lichenase [EC 3.2.1.73] \\
\hline & $\begin{array}{l}\text { Orf_2294, Orf_2388, Orf_2464, } \\
\text { Orf_2606, Orf_3385, Orf_401, } \\
\text { Orf_403, Orf_404, Orf_922 }\end{array}$ & $\beta$-glucosidase [EC 3.2.1.21] \\
\hline & Orf_2704, Orf_2893 & Oligo-1,6-glucosidase [EC 3.2.1.10] \\
\hline & Orf_2898 & Maltodextrin glucosidase [EC 3.2.1.20] \\
\hline & Orf_802 & $\begin{array}{l}\text { Glucan endo-1,3- } \beta \text {-glucosidase } \quad[\mathrm{EC} \\
3.2 .1 .39]\end{array}$ \\
\hline & Orf_3703 & $\beta$-galactosidase [EC 3.2.1.23] \\
\hline & Orf_2449 & $\begin{array}{l}\text { Trehalose-6-phosphate hydrolase [EC } \\
\text { 3.2.1.93] }\end{array}$ \\
\hline & Orf_102 & Pectate trisaccharide-lyase [EC 4.2.2.22] \\
\hline & Orf_1326 & Pectate lyase [EC 4.2.2.2] \\
\hline & Orf_19, Orf_21 & Levanase [EC 3.2.1.80] \\
\hline & Orf_20 & $\begin{array}{l}\text { Levanbiose-producing levanase }[\mathrm{EC} \\
\text { 3.2.1.64] }\end{array}$ \\
\hline & Orf_22 & Levansucrase [EC 2.4.1.10] \\
\hline \multirow[t]{9}{*}{$\begin{array}{l}\text { Hemicellulose- } \\
\text { related }\end{array}$} & Orf_905 & $\begin{array}{l}\text { Mannan endo-1,4- } \beta \text {-mannosidase [EC } \\
\text { 3.2.1.78] }\end{array}$ \\
\hline & Orf_3988, Orf_4004 & $\begin{array}{lr}\text { Bifunctional } & \beta \text {-xylosidase } / \alpha- \\
\text { arabinosidase } & \text { EC 3.2.1.37; EC 3.2.1.55] }\end{array}$ \\
\hline & Orf_4003 & $\begin{array}{l}\text { Arabinoxylan arabinofuranohydrolase } \\
\text { [EC 3.2.1.55] }\end{array}$ \\
\hline & Orf_35, Orf_2605 & $\alpha$-xylosidase [EC 3.2.1.177] \\
\hline & $\begin{array}{l}\text { Orf_24, Orf_2083, Orf_3386, } \\
\text { Orf_3999, Orf_4000, Orf_4002 }\end{array}$ & $\alpha$-L-arabinofuranosidase [EC 3.2.1.55] \\
\hline & Orf_34, Orf_3650, Orf_4001 & $\begin{array}{l}\text { Non-reducing end } \beta \text {-L- } \\
\text { arabinofuranosidase [EC 3.1.1.185] }\end{array}$ \\
\hline & Orf_3698 & $\begin{array}{l}\text { Exo- } \alpha-(1->6)-L-a r a b i n o f u r a n o s i d a s e \\
\text { [EC 3.2.1.- }\end{array}$ \\
\hline & Orf_1000, Orf_2117, Orf_3772 & Endo-1,4- $\beta$-xylanase [EC 3.2.1.8] \\
\hline & Orf_266, Orf_2247 & $\alpha$-galactosidase [EC 3.2.1.22] \\
\hline
\end{tabular}


